\title{
Toward an Operational Bare Soil Moisture Mapping Using TerraSAR-X Data Acquired Over Agricultural Areas
}

\author{
Maëlle Aubert ${ }^{1}$, Nicolas Baghdadi ${ }^{2}$, Mehrez Zribi ${ }^{3}$, Kenji Ose ${ }^{2}$, Mahmoud El Hajj ${ }^{4}$, Emmanuelle Vaudour ${ }^{5}$, and \\ Enrique Gonzalez-Sosa ${ }^{6}$ \\ 1- CNES-Noveltis, UMR TETIS, BP 5095, Montpellier, France (e-mail: maelle.aubert@teledetection.fr). \\ 2- IRSTEA, UMR TETIS, BP 5095, Montpellier, France (e-mail: nicolas.baghdadi@teledetection.fr) \\ 3- CESBIO, 31041 Toulouse, France (e-mail: mehrez.zribi@ird.fr). \\ 4- Noveltis, 31520 Ramonville-Saint Agne, France (e-mail: mahmoud.elhajj@noveltis.fr). \\ 5- INRA AgroParisTech UMR10091 EGC, 78850 Thiverval-Grignon, France (e-mail: emmanuelle.vaudour@agroparistech.fr). \\ 6- IRSTEA,URHHLY, CP 220, F-69336 Lyon, France and DEFI-CIAQ, Université de Querétaro, CU Cerro de las Campanas. S/N. \\ Centro. 6900 Queretaro, Qro., Mexico (e-mail egs@uaq.mx).
}

Abstract-TerraSAR-X data are processed for an operational mapping of bare soils moisture in agricultural areas. Empirical relationships between TerraSAR-X signal and soil moisture were established and validated over different North European agricultural study sites. The results show that the mean error on the soil moisture estimation is less than $4 \%$ regardless of the TerraSAR-X configuration (incidence angle, polarization) and the soil surface characteristics (soil surface roughness, soil composition). Furthermore, the potential of TerraSAR-X data (signal, texture features) to discriminate bare soils from other land cover classes in an agricultural watershed was evaluated. The mean signal backscattered from bare soils can be easily differentiated from signals from other land cover classes when the neighboring plots are covered by fully developed crops. This was observed regardless of the TerraSAR-X configuration and the soil moisture conditions. When neighboring plots are covered by early growth crops, a TerraSAR-X image acquired under wet conditions can be useful for discriminating bare soils. Bare soil masks were calculated by object-oriented classifications of mono-configuration TerraSAR-X data. The overall accuracies of the bare soils mapping were higher than $84 \%$ for validation based on object and pixel. The bare soils mapping method and the soil moisture relationships were applied to TerraSAR-X images to generate soil moisture maps. The results show that TerraSAR-X sensors provide useful data for monitoring the spatial variations of soil moisture at the within-plot scale. The methods of bare soils moisture mapping developed in this paper can be used in operational applications in agriculture, and hydrology.

\section{Index Terms - SAR, soil moisture, map, X-band, TerraSAR-X, within field plot scale}

\section{INTRODUCTION}

$\mathrm{O}$ UR Earth is not the desolate planet depicted in the famous science fiction novel "Dune" [1]; however, its water is a precious and often scarce resource. Soil moisture is the lifegiving substance for crop growth and governs the proportion of rainfall that percolates, is lost to runoff, or evaporates from the land. Soil moisture has also been widely recognized as a key variable of the water cycle in numerous environmental studies focusing on climate change, flood forecasting, crop monitoring, and other applications [2]-[3]. For sustainable development to occur, operational tools for evaluating land management scenarios, providing sound references for natural resource protection, and targeting land use planning are required. Therefore, it is important to accurately monitor and estimate spatial and temporal variations of soil moisture. Moreover, because essentially bare soils are associated with a considerable risk of runoff and erosion in agricultural areas [4], maintaining soil moisture over bare soil surfaces is especially important.

Active and passive microwave sensors have already shown their potential for use in soil moisture estimations, regardless of the weather conditions, over a vast surface and at regular time intervals. Currently, a variety of sensors with various ranges of spatial resolution are available. Some of these provide estimates of soil moisture at low resolutions that are suitable for regional or global climatic studies (ERS/WSC, ASCAT/METOP, and SMOS) [5]-[6]-[7]; others, such as ERS, Envisat/ASAR, TerraSAR-X, RADARSAT, and Palsar/ALOS, provide soil moisture estimations at high spatial resolution (better than $30 \mathrm{~m}$ ) to provide a diagnosis suited to agricultural watershed areas (e.g., [8]-[9]-[10]).

It is well known that the SAR (Synthetic Aperture Radar) backscattered signal from bare soils is a function of the sensor configuration, which includes the wavelength, polarization, and incidence angle, as well as the soil surface characteristics such as soil moisture and surface roughness [11]-[12]-[13][14]. A major limiting factor in the estimation of bare soil moisture is the separation of the individual scattering effects of soil moisture and surface roughness. Moreover, the estimation of soil moisture is even more complicated in the case of single-configuration SAR observations (one SAR datum and at least two unknowns, such as the soil moisture and surface roughness), leading to an underdetermined problem. Thus, with only one image acquired at one incidence and one polarization, the estimation of bare soil surface moisture requires knowledge of the relationship between the radar signal and the soil moisture regardless of the surface roughness. To overcome the effect of soil roughness on soil moisture estimation processes conducted using only one set of SAR data (one incidence and one polarization), methodologies have been developed based on empirical relationships or 
multi-incidence SAR acquisitions.

For retrieving bare soil moisture from single SAR data at Cand L-bands, some approaches based on empirical relationships between radar signal and soil moisture are used without taking the soil roughness into account [15]-[9]-[16][17]-[18]. These methods are based on linear or logarithmic regressions between in situ soil moisture measurements and radar signals for each SAR configuration (incidence, polarization, and radar wavelength). At C- and L-bands, soil moisture estimation has shown that the coefficients that describe the relationship between the SAR signal and soil moisture may depend on watershed soil surface characteristics such as soil surface roughness and soil composition [9]. In the X-band, investigations with TerraSAR-X data have demonstrated high sensitivity of the radar signal to soil moisture and low sensitivity to agricultural surface roughness [19]. Moreover, the TerraSAR-X signal was not directly sensitive to the soil composition of bare agricultural plots [19]-[20].

To overcome the influence of soil roughness on soil moisture estimation, other methods based on multi-incidence SAR images have been developed. When two images acquired at different incidence angles, one low and one high, are used, it is typically assumed that the soil roughness remains unchanged between the two acquisitions and that the change in backscattered signal is due to a change in soil moisture. Several studies using C-band data have shown that the use of two incidence angles improves soil moisture estimation in comparison with results obtained using only one incidence angle [21]-[22]-[10]. The high temporal repetitiveness of the TerraSAR-X sensor permits the acquisition of image pairs at low and high incidence angles at the same study site within one day. Nevertheless, [23] have demonstrated that the accuracy of soil moisture estimates based on TerraSAR-X data is not improved when two incidence angles $\left(26^{\circ}-28^{\circ}\right.$ or $50^{\circ}$ $52^{\circ}$ ) are used instead of one. Thus, TerraSAR-X data at a single incidence angle are sufficient to estimate soil moisture [23].

In the operational process of bare soil moisture mapping, the greatest challenge may be bare soil detection from SAR images. Commonly, bare soil detection is conducted using optical or in situ data [24]-[9]-[18]. Nevertheless, due to cloud cover, it is sometimes difficult to acquire optical images from dates close to those of the SAR acquisitions, especially during the autumn and winter seasons. Moreover, to reduce the cost of operational soil moisture mapping from SAR images, it would be very useful to extract the bare soils from these same SAR images.

Previous studies have shown that the SAR signal is correlated with the NDVI (Normalized Vegetation Index); consequently, the SAR signal can be used to detect bare soil from vegetation cover. At the L-band, the signal ratio $\mathrm{HV} / \mathrm{VV}$ can be used to distinguish bare soils from vegetation cover [25]. Using single SAR images, [12] indicated that the classification of bare surface, short and tall vegetation reached an accuracy of approximately $75 \%$ at the C-band $\left(\mathrm{VV}-23^{\circ}\right)$ and of approximately $98 \%$ at the L-band $\left(\mathrm{HH}-35^{\circ}\right)$. Using both C- and L-band data at $\mathrm{HV}$ and $\mathrm{HH}$ polarizations, the classification accuracy of bare soil from vegetation cover is approximately 98\% [26]. Recently, [27] showed that bare soil areas could be distinguished from areas with short and tall vegetation using PALSAR polarimetric data (L-band).

At the X-band, previous studies on sugarcane have shown that X-band signals increase with NDVI [28]. Nevertheless, few studies have used the X-band to distinguish bare soil from other landcover. Preliminary studies have been conducted on the potential of using TerraSAR-X classification to discriminate different types of forests and crops. Using TerraSAR-X time series acquired during the spring and summer, crop types could be classified with an accuracy of $78.5 \%$ using $\mathrm{VV}$ polarization and with an accuracy of $90.4 \%$ using dual polarization (VV, VH) [29]. Reference [30] proposed landcover classification into urban area, agricultural, forest, and open water using single TerraSAR-X data acquired in the summer. The results of that study yielded an overall accuracy of approximately $94 \%$ for both $\mathrm{HH}$ and $\mathrm{VV}$ polarizations $(88 \%$ with $\mathrm{HH}$ alone and $90 \%$ for $\mathrm{VV}$ alone). HH polarization was slightly better suited to separate forest and urban areas, whereas the use of VV polarization permitted better separation of forest and agricultural lands [30]. Moreover, a variety of studies have shown that the use of both texture and signal data improves the classification accuracy of agricultural cover (crops and forest) because the information content of an image depends both on each pixel's intensity (signal) and on the spatial arrangement of pixels[31][32]-[33]-[13]. Using TerraSAR-X data acquired in the spring, [34] showed that, when Haralik texture and signal are used together, crop type classification can reach an overall accuracy of $95 \%$.

Finally, landcover mapping from SAR images is most appropriately performed using an object-based approach rather than a pixel-based method because the grouping of neighboring pixels into objects based on similar properties results in minimization of the SAR speckle noise. Reference [35] have shown that the optimum scale for mapping agricultural areas is the plot scale because of the inherent plot structure of such areas.

The present study proposes an operational methodology for soil moisture mapping over bare soils that is based only on TerraSAR-X data. An empirical soil moisture estimation algorithm will be developed and validated over several agricultural study sites. The potential of TerraSAR-X data for mapping bare soils will also be investigated for different TerraSAR-X configurations, soil moisture conditions, and crop growth stages. Finally, an operational mapping process of soil moisture that proceeds from bare soil detection to soil moisture estimation will be carried out over a TerraSAR-X time series. All processes are based on a single configuration of TerraSAR-X data, thus reducing both processing time and cost. 


\section{MATERIALS AND METHODS}

\section{A. Study Sites}

Six sites were used in this study. These sites are located in contrasting geographic and climatic environments, a feature that allowed us to test the robustness and the transferability of the approaches that were developed (Fig. 1).

- Orgeval watershed: This study site is located to the east of Paris, France (Lat. $48^{\circ} 51^{\prime} \mathrm{N}$; Long. $3^{\circ} 07^{\prime} \mathrm{E}$ ). The main land use is arable farming for wheat and maize. The terrain is flat, and the topsoil composition is predominantly loamy (17\% clay, $78 \%$ silt, and $5 \%$ sand). This soil composition promotes crust development, which increases soil sealing and causes runoff [36]-[37]. The Orgeval watershed has been managed since 1962 as an experimental basin for hydrological research by the National Research Institute of Science and Technology for Environment and Agriculture (IRSTEA).

- Versailles plain: This study site is located near Paris, France (Lat. $48^{\circ} 51^{\prime} \mathrm{N}$; Long. $1^{\circ} 58^{\prime} \mathrm{E}$ ). Its territory is characterized by a discontinuous urban fabric and intensive development of agricultural activities. Due to its geographical proximity to the Parisian urban zone, this agricultural territory recycles considerable organic waste through agricultural activities. It is flat, and its topsoil composition is predominantly loamy ( $24 \%$ clay, $59 \%$ silt, and $17 \%$ sand).

- Villamblain site: This study site is located southwest of Paris, France (Lat. $48^{\circ} 00^{\prime} \mathrm{N}$; Long. $1^{\circ} 34^{\prime} \mathrm{E}$ ). It is characterized by large agricultural fields, and the main crops are wheat and corn. It is flat, and its topsoil composition is loamy (30\% clay, $60 \%$ silt, and $10 \%$ sand).

- Yzeron watershed: This study site is located southwest of Lyon, France (Lat. $45^{\circ} 46^{\prime} \mathrm{N}$; Long. $4^{\circ} 39^{\prime} \mathrm{E}$ ). It is a peri-urban watershed that is regularly subjected to flooding. Its land use is dominated by forest, pasture and crops, although a significant part of the catchment is heavily impacted by human activity. The topography is very marked, with slope gradients of over $10 \%$. Its topsoil composition is predominantly sandy loam ( $13 \%$ clay, $20 \%$ silt, and $67 \%$ sand).

- Thau watershed: This study site is located near Montpellier, France (Lat. $43^{\circ} 26^{\prime} \mathrm{N}$; Long. $3^{\circ} 40^{\prime} \mathrm{E}$ ). Its land is primarily used for cereal crops (wheat) and vineyards. The soil composition is predominantly loamy (35\% clay, $52 \%$ silt, and $12 \%$ sand).

- Garon site: This study site is located near Montpellier, France (Lat. $43^{\circ} 45^{\prime} \mathrm{N}$; Long. $4^{\circ} 23^{\prime} \mathrm{E}$ ). It is flat and characterized by highly diversified agricultural use (field crops, orchards, vineyards, market gardens, meadows, and fallow land). The soil composition is predominantly loamy ( $40 \%$ clay, $54 \%$ silt, and $6 \%$ sand).

\section{B. TerraSAR-X Data}

Thirty-nine TerraSAR-X images were acquired between 2008 and 2010. The images are acquired in spotlight mode (pixel spacing $\sim 1 \mathrm{~m}$ ), with incidence angles between $23^{\circ}$ and $54^{\circ}$ and using $\mathrm{HH}$ or VV polarization (Table 1).

TerraSAR-X data were radiometrically calibrated using the following equation (1) [38]:

$$
\begin{array}{r}
\sigma^{\circ}(\mathrm{dB})=10 . \log _{10}\left(\mathrm{Ks} . \mathrm{DNi}^{2}-\mathrm{NEBN}\right) \\
+10 \cdot \log _{10}\left(\sin \theta_{i}\right)
\end{array}
$$

This equation converts the digital number of each pixel $\left(D N_{i}\right)$ into a backscattering coefficient in decibels $\left(\sigma_{i}^{\circ}\right)$ that is corrected for sensor noise (NEBN). This calibration process takes into account the radar incidence angle $\left(\theta_{i}\right)$ and a calibration constant $(\mathrm{Ks})$ provided in the image data. The images were then georeferenced using aerial orthophotographs (50 $\mathrm{cm}$ spatial resolution). The root mean square error of the control points was approximately one pixel (i.e., $1 \mathrm{~m}$ ). For the Yzeron data, a radiometric terrain correction was performed with the radiometric correction module implemented in the ERDAS Leica geosystem software using a Lidar DEM (2 m spatial resolution). The use of these calibration processes not only permitted multi-temporal analysis of different images of a single study site but also made possible the comparison of radar signals between the different study sites.

Finally, the dataset was divided into four sets, as described below (Table 1):

SMAC (Soil Moisture Algorithm Calibration) was used to define relationships between radar signals and soil moisture (182 plots measured in situ: Orgeval 2009, Versailles, Villamblain);

SMAV (Soil Moisture Algorithm Validation) was used to validate the relationships between radar signals and soil moisture derived from the SMAC dataset and to test the robustness of these relationships (121 plots measured in situ: Yzeron, Thau, Garon, Orgeval 2010);

BSD (Bare Soil Detection) was used to evaluate the potential of TerraSAR-X data for bare soil mapping (Orgeval 2009 and 2010);

BSMOM (Bare Soil Moisture Operational Mapping) was used to test the applicability of the bare soil moisture operational mapping method (48 plots measured in situ: Orgeval 2010).

\section{Optical Data}

Optical data are used both to identify training objects and to validate the accuracy of the TerraSAR-X bare soil mapping approaches (Table 2). In a first step, optical images were calibrated in 'Top Of the Atmosphere' (TOA) reflectance and georeferenced using aerial orthophotographs $(50 \mathrm{~cm}$ spatial resolution). The NDVI images were then calculated from each image in TOA spectral reflectance. Oriented object classifications were then conducted to obtain landcover maps from each optical image using eCognition software. Segmentation processes were based on the NDVI image because it is the best feature by which to differentiate bare soil from vegetation and because it permits easily obtaining homogenous objects without jagged boundaries at field scale. Table 3 lists the segmentation parameters that were used. Once each image had been segmented, different rules were used to differentiate bare soil, developed crop, sprouting crop, 
open water, forest and urban areas. Rules were based on the mean and standard deviation of the NDVI, the mean and standard deviation of the spectral values, and on border features (the ratio between the border lengths of the image object and the smallest enclosing rectangle). Border features were used to differentiate bare and sprouting crops from urban objects; this was possible because the shapes of urban objects are strongly jagged, whereas crops have a compact shape.

The comparison of landcover maps obtained from optical images with in situ observations and expert photointerpretation showed good agreement. Bare soils are very well identified, but there is sometimes confusion between bare soils and urban areas. Moreover, pixels of images of forests and developed crops are sometimes mixed in the same object during the segmentation process. As a result, after the classification process, some confusion between forest and developed crop areas persisted.

To evaluate the potential of TerraSAR-X data in differentiating bare soils from other landcover classes, the same training objects were used from the beginning (March) to the end (May) of the 2009 time series and from the beginning (March) to the end (March) of the 2010 time series. For the 2009 BSD TerraSAR-X dataset, training plots are identified from IKONOS and SPOT-5 landcover maps (Fig. 2). Only training plots classified as bare soil, forest, or developed crop on both IKONOS and SPOT-5 landcover maps were selected. Consequently, possible inaccuracies in the IKONOS and SPOT-5 landcover maps due to classification or segmentation were overcome. In our separability study, urban areas and open waters are not used because they are easily detectable on TerraSAR-X images. Moreover, because sprouting crops and bare plots give similar TerraSAR-X signals, their separation is not possible. Consequently, sprouting crops are not studied.

For the 2010 BSD dataset, only one optical image acquired in May is available on the Orgeval study site, whereas the TerraSAR-X time series was acquired in March (Table 1). Nevertheless, all bare soils and forests in the landcover map of May 2010 were also bare soils and forests in March (TerraSAR-X acquisitions). Of the plots identified as developed crops on the landcover map in May, only the plots with the highest NDVI were assumed be developed crops in March. These plots were selected as training plots and were used to analyze the potential of the TerraSAR-X data for distinguishing bare soil from the other landcover classes.

Finally, to test the accuracy of the bare soil map obtained from the BSMOM TerraSAR-X dataset (Table 1), a reference bare soil map is created from the RapidEye landcover map (Fig. 8). To accomplish this, each pixel classified as bare soil or sprouting crops in the RapidEye landcover map of May 2010 is classified as bare soil in the bare soil map of validation of March 2010. The fact that sprouting crops in May were bare soils in March is confirmed by the fact that two bare soils measured in situ in March 2010 are classified as sprouting crops in the RapidEye May 2010 landcover map. Moreover, this observation is coherent with the evolution observed in the 2009 TerraSAR-X time series: sprouting crops in the SPOT-5 landcover map were bare soil in the IKONOS landcover map. All other pixels are classified in the 'other' class (Fig. 8).

\section{Ground Measurements}

Simultaneously with TerraSAR-X acquisitions (between 2008 and 2010), ground measurements of soil moisture and surface roughness were obtained on several bare training plots. Gravimetric and TDR (time-domain reflectometry probe) soil moistures were collected over depths of $0-5 \mathrm{~cm}$ at the time of the satellite overpasses. For each training plot, twenty gravimetric samples were taken and 20 to 40 TDR measurements were performed. Gravimetric measurements were converted into volumetric moisture (mv) based on bulk density. The location of each in situ measurement was recorded using a GPS device. The soil moisture of each training plot was assumed to be equal to the mean value estimated from the measurements collected in each training plot. Ground surveys conducted between 2008 and 2010 produced soil moisture values ranging between $5.7 \%$ and $40.6 \%$ (Table 1).

Soil roughness measurements were also conducted using ten profiles of a $1 \mathrm{~m}$ long profilometer with a $2 \mathrm{~cm}$ sampling interval. The surface roughness of a given bare soil is defined statistically using the standard deviation of surface height (Hrms) and the correlation length (L). The Hrms values of the plots obtained during the ground surveys varied between 0.4 and $4.6 \mathrm{~cm}$ (Table 1). The lowest values $(0.4$ to $1.5 \mathrm{~cm})$ corresponded to recently sown plots, whereas the highest values (above $1.5 \mathrm{~cm}$ ) corresponded to winter and recently ploughed plots. The correlation length (L) varied from $1.7 \mathrm{~cm}$ in sown plots to $9.3 \mathrm{~cm}$ in ploughed plots. Thus, data collected between 2008 and 2010 covered a very wide range of soil surface conditions (dry to wet and smooth to rough).

\section{RESULTS}

\section{A. Sensitivity of TerraSAR-X signals to soil moisture}

The SMAC dataset (Table 1) was used to establish empirical relationships between the backscattered signal and the in situ soil moisture. At C- or L-bands, it is commonly assumed that the backscattered signal of bare soils can be formulated as the sum of a function dependent on soil moisture (f) and a function dependent on surface roughness (g) [21]-[10]. Early investigations showed a logarithmic dependence between the radar signal and the soil moisture [39]-[17]. This logarithmic function could be approximated by a linear relationship for moisture contents between 10-15\% and $35-40 \%$ (e.g., [21], [40]). The relationship between the radar signal and the soil surface roughness is exponential [15][10]. The backscattered signal $\left(\sigma^{\circ}\right)$ can be written as $(2)$ :

$$
\sigma^{\circ}(\mathrm{dB})=\mathrm{f}(\mathrm{mv}, \theta, \mathrm{pp}, \mathrm{k}) \mathrm{dB}+\mathrm{g}(\mathrm{Hrms}, \theta, \mathrm{pp},
$$$$
\text { k) } \mathrm{dB}+\mathrm{C}
$$

for $10-15 \%<\mathrm{mv}<35-40 \%$ : 


$$
\begin{aligned}
& \quad=\mathrm{A} \cdot \mathrm{mv}+\mathrm{B} \text { e }-\mathrm{k} \cdot \operatorname{Hrms}+\mathrm{C} \\
& \text { for } 5 \%<\mathrm{mv}<40 \% \text { : } \\
& =\mathrm{A} \cdot \ln (\mathrm{mv})+\mathrm{B} \text { e }-\mathrm{k} \cdot \operatorname{Hrms}+\mathrm{C}
\end{aligned}
$$

where $\mathrm{k}$ is the radar wave number, $\theta$ is the radar incidence angle (degree), $\mathrm{pp}$ is the polarization and (A, B, C) correspond to coefficients that depend on the radar incidence angle, polarization, and radar wave number. In the X-band, for bare agricultural plots, the effect of soil roughness on the TerraSAR-X signal is low and is mainly a function of the moisture content [19].

In the case of single SAR configurations (one incidence and one polarization), the bare agricultural soil moisture estimate requires that the relationship between the backscattered signal and the soil moisture be determined without taking into account the soil roughness (e.g., [15]-[41]). In our study, the SMAC dataset (Table 1) included soil moisture values below and above $15 \%$. Consequently, the backscattered signal was described by a logarithmic function of soil moisture. Thus, the relationship between the SAR signal and soil moisture can be written as follows (3):

$$
\sigma^{\circ}(\mathrm{dB})=\mathrm{A} \cdot \ln (\mathrm{mv})+\beta
$$

For a given SAR configuration, the sensitivity of the SAR signal to soil moisture (A) is principally controlled by the SAR acquisition configuration (incidence angle, polarization, and radar wavelength). To determine the coefficients $A$ and $\beta$, the mean backscattering coefficient calculated for each training plot of the SMAC dataset was plotted as a function of in situ soil moisture regardless of soil roughness. TerraSAR-X data acquired at $\mathrm{HH}$ and $\mathrm{VV}$ polarizations were plotted together because they are very well correlated [42]-[28]. One graphic was created for each range of incidence angle $\left(25^{\circ}\right.$ and $33^{\circ}, 50^{\circ}$ and $54^{\circ}$ ) (Fig. 3).

Fig. 3 shows that the sensitivity of TerraSAR-X signals to soil moisture is higher for a low incidence angle and low soil moisture than for a high incidence angle and high soil moisture. However, the dependence of the TerraSAR-X signal on soil moisture shows high sensitivities for both low and high incidence angles $\left(0.34 \mathrm{~dB} / \%\right.$ at $25^{\circ}-33^{\circ}$ and $0.28 \mathrm{~dB} / \%$ at $50^{\circ}$ $54^{\circ}$ for moisture contents between $15 \%$ and $40 \%$ ). In conclusion, the estimation of bare soil moisture using mono configuration TerraSAR-X data could be performed with either low $\left(25^{\circ}-33^{\circ}\right)$ or high $\left(50^{\circ}-54^{\circ}\right)$ incidence angles, regardless of the polarization ( $\mathrm{HH}$ or $\mathrm{VV}$ ). In comparison with C-band studies, the sensitivity of the TerraSAR-X signal to soil moisture appears to be higher in the X-band than in the Cband data, regardless of the incidence angle (e.g., [8]-[9][43]). Indeed, the relationship between the radar signal at the $\mathrm{C}$-band and soil moisture varies commonly between 0.15 $\mathrm{dB} / \%$ and $0.3 \mathrm{~dB} / \%$ according to the incidence angle and the characteristics of the study sites.

The estimation of soil moisture from TerraSAR-X data is based on the inversion of the relationships established between $\sigma^{\circ}$ and $\mathrm{mv}$ from the SMAC dataset (3) (Fig. 3). A linear interpolation of the relationships obtained for low $\left(25^{\circ}-33^{\circ}\right)$ and high $\left(50^{\circ}-54^{\circ}\right)$ incidence angles was also performed to compute the coefficients of the relationship between $\sigma^{\circ}$ and $\mathrm{mv}$ for $40^{\circ}$ (4). Thus, the soil moisture estimation using single TerraSAR-X configuration can be obtained from the following relationships (4):

$$
\begin{aligned}
& \mathrm{HH} \text { and } \mathrm{VV} \text { at } 25^{\circ}-33^{\circ} \\
& \mathrm{mv}=\mathrm{e}\left[\left(\sigma^{\circ}(\mathrm{dB})+33.167\right) / 8.8054\right] \\
& \mathrm{HH} \text { and } \mathrm{VV} \text { at } 50^{\circ}-54^{\circ} \\
& \mathrm{mv}=\mathrm{e}\left[\left(\sigma^{\circ}(\mathrm{dB})+30.974\right) / 6.9482\right] \\
& \mathrm{HH} \text { and } \mathrm{VV} \text { at } 40^{\circ} \\
& \mathrm{mv}=\mathrm{e}\left[\left(\sigma^{\circ}(\mathrm{dB})+32.120\right) / 7.9190\right]
\end{aligned}
$$

\section{B. Validation of relationships between radar signal and soil moisture}

The SMAV dataset (Orgeval 2010, Yzeron, Thau, Garon) was used to test the robustness of the relationships between TerraSAR-X signals and soil moisture. In a first step, the mean backscattering coefficient was calculated for each bare training plot of the SMAV dataset. Then, according to the incidence angle of the TerraSAR-X image, the relationship between $\mathrm{mv}$ and $\sigma^{\circ}$ defined in (4) is used to invert the backscattered signal into soil moisture. The inversion procedure was performed using TerraSAR-X data acquired at $\mathrm{HH} 23^{\circ}-25^{\circ}, \mathrm{VV} 26^{\circ}-35^{\circ}, \mathrm{VV} 52^{\circ}$, and VV-41 ${ }^{\circ}$ (Table 1 ). The TerraSAR-X soil moisture estimates were compared to the in situ soil moisture measurements. The comparisons showed good agreement between the estimated and measured soil moistures (Table 4 and Fig. 4).

The soil moisture was estimated with a Root Mean Square Error (RMSE) of $3.8 \%$ (mean bias $=0.7 \%$ ) when all of the site-by-site data were pooled; the error ranged from $2.5 \%$ to $5.0 \%$ (Table 4). Moreover, the TerraSAR-X soil moisture estimation accuracy is of the same order at low and at high incidence angles (RMSE $=3.7 \%$ for $\mathrm{HH}$ and VV polarizations and incidence angles between $23^{\circ}$ and $35^{\circ}, 2.1 \%$ for $\mathrm{VV}-41^{\circ}$, and $4.5 \%$ for $\mathrm{HH}$ and $\mathrm{VV} 49^{\circ}-52^{\circ}$ ). The accuracy of the soil moisture estimates derived from TerraSAR-X data is of the same order for sandy loam (Yzeron) and for loamy soil compositions (Orgeval, Thau, and Garon) (Table 4). In summary, the results show that relationship between the TerraSAR-X signal and soil moisture is robust regardless of the study site and the TerraSAR-X configuration. High and low incidence angles $\left(23^{\circ}\right.$ to $\left.52^{\circ}\right)$ both give satisfactory performance $(\mathrm{RMSE}<4 \%)$.

\section{Potential of TerraSAR-X data for bare soil detection}

For soil moisture mapping from SAR images over bare agricultural areas, it is essential that the bare soil map be available. Commonly, the bare soil map is obtained by classifying optical images (e.g., [23]-[9]-[18]). Nevertheless, due to bad weather conditions during the autumn and winter, it is sometimes difficult to acquire optical images from dates 
close to those of the SAR acquisitions. Moreover, it would be operationally very useful to extract the bare soils from these same SAR images. Thus, it is important to be able to create bare soil maps without optical data and from the primary TerraSAR-X data of the time series.

The potential of TerraSAR-X data to differentiate bare soil from other landcover classes was evaluated using the BSD dataset acquired over the Orgeval study site in 2009 and 2010 (Table 1). This analysis allows us to determine the best SAR configuration (incidence angle) and the optimal soil moisture conditions for bare soil mapping from TerraSAR-X data. Training objects with their landcover class identified from optical landcover maps allow us to validate the potential of TerraSAR-X data for use in differentiating bare soil from other landcover classes such as forest areas and crops.

\section{1) Effect of TerraSAR-X configurations and soil moisture conditions}

The objective of this study is to determine the best TerraSAR-X incidence angle and the optimal soil moisture condition to differentiate bare soil from forest and crops. For each TerraSAR-X image, the mean and the standard deviation of the TerraSAR-X signal is calculated for each landcover class using all training plots of each class. The signal of each landcover class is then analyzed with respect to soil moisture conditions for three incidence angles: low $\left(25^{\circ}\right)$, medium $\left(40^{\circ}\right)$ and high $\left(50^{\circ}\right)$ (Fig. 5). Because $\mathrm{HH}$ and VV are strongly correlated in the X-band for vegetation cover [28]-[44], HH and VV polarization are analyzed together. Reference [28] observed that, for bare soils and crops, the HH response in the $\mathrm{X}$-band is slightly higher than that of the VV response (less than $1 \mathrm{~dB}$ ).

As shown, the backscattered signal of bare soils follows the behavior of the soil moisture regardless of the TerraSAR-X acquisition parameters (i.e., incidence angle) (Fig. 5). For example, the signal of bare soils for $\mathrm{HH}-25^{\circ}$ decreases by 6.8 dB between March 26 and April 17, 2009 for a decrease of soil moisture of $13.1 \%$. Moreover, the TerraSAR-X signal dynamic with the moisture content of bare soils is higher at a low incidence angle $\left(25^{\circ}\right)$ than at a high incidence angle $\left(50^{\circ}\right)$ [19].

In the two BSD TerraSAR-X time series $(2009,2010)$, the forest signal at $\mathrm{HH}$ polarization is almost constant $( \pm 1 \mathrm{~dB})$ for each incidence angle $\left(25^{\circ}\right.$ and $\left.50^{\circ}\right)$ regardless of the soil moisture content (Fig. 5). This is due to the low penetration depth of the X-band in the forest cover (almost zero). The standard deviation of the backscattered signal from forest is constant and below $1 \mathrm{~dB}$ whatever the TerraSAR-X configuration (incidence angle, polarization). At the beginning of crop growth (approximately April 17, 2009), the TerraSAR$\mathrm{X}$ signal backscattered from crops (mainly winter wheat) is dominated by direct backscatter from the soil. Indeed, the TerraSAR-X signal follows the in situ soil moisture variation regardless of the incidence angle $\left(25^{\circ}\right.$ and $\left.50^{\circ}\right)$ (Fig. 5). This result confirms the results of previous studies in which it was demonstrated that the TerraSAR-X signal can penetrate the vegetation cover at the early crop stage [28]. Indeed, between
March and April 2009, the measured wheat height over the Orgeval study site varies between 10 and $20 \mathrm{~cm}$. Moreover, the wide TerraSAR-X time series of 2009 at the incidence angle of $25^{\circ}$ allows us to observe the multitemporal backscattered signal behavior of wheat crops. After April 17, 2009 , the direct soil contribution is attenuated by the presence of stems. The backscattered signal obtained on April 28, 2009 is dominated by direct scatter from the leaves and stems; later, on May 11, 2009, it is strongly affected by scatter from the ears. The contribution of the stems is also important in the final growth phase. This result is in agreement with the results of many other studies [45]-[44]. Regardless of the incidence angle, the standard deviation of the backscattered signal from the crops is approximately $1.5 \mathrm{~dB}$ during the early season. For developed crops from April 27 to May 11, 2009, the standard deviation is approximately $2.5 \mathrm{~dB}$ at $25^{\circ}$ and $3.6 \mathrm{~dB}$ at $50^{\circ}$.

In conclusion, at the early crop growth stage, although the signal from crops is slightly attenuated by the vegetation cover, the total backscattered signal is dominated by the direct soil backscatter (i.e., by soil moisture). The signal difference between bare soil and crops is slightly greater at $25^{\circ}$ than at the $50^{\circ}$ incidence angle. Moreover, this difference is greater at high $(>25 \%)$ than at low soil moistures. The signal difference between bare soils and crops increases with crop growth, and this difference becomes important under all soil moisture conditions when crops are developed. The signal difference between bare soils and forest is important for TerraSAR-X data acquired at wet $(25-30 \%)$ and dry $(<10-15 \%)$ soil moisture conditions regardless of the TerraSAR-X incidence angle. For a soil moisture content of approximately $15 \%$, forests and bare soils have similar TerraSAR-X signals at $25^{\circ}$ and $50^{\circ}$ incidence angles. Indeed, the forest signal is almost constant at these two angles, and its value is of the same order as the signal value obtained from bare soils with a moisture content of approximately $15-20 \%$.

\section{2) Separability between landcover classes}

Previous studies have shown that the use of both SAR signals and textural features improves the SAR classification of different types of crops [34] or forests [30]-[13]. To test the potential of textural features in differentiating bare soils from forests and crops, 64 textural features are calculated in addition to the SAR signal (mean and standard deviation computed at plot scale); these include the 4 textural features described by [46] (computed from windows $7 \mathrm{x} 7$ pixels in size and averaged at plot scale) and the 12 textural features defined by [47] and computed for 5 directions (all directions, $0^{\circ}, 45^{\circ}$, $90^{\circ}$, and $135^{\circ}$ ) (Table 5).

Textural and signal features are computed for each training object (Table 4) and each TerraSAR-X image of the BSD dataset (Table 1).

To reflect the overall classification accuracy that will be attained in using a feature to differentiate bare soil from crops or forest, the Jeffry-Matusita distance is used. Indeed, the Jeffries-Matusita distance measures the separability between two classes on a scale of 0 to 2 , as described by the following equation (5): 


$$
\mathrm{J}=2\left(1-\mathrm{e}^{-\mathrm{B}}\right)
$$

where $\mathrm{B}$ is the Bhattacharyya distance [48].

Total separability between two classes in using a given feature is indicated by $\mathrm{J}=2$ (no misclassifications). The lower the $\mathrm{J}$ value, the poorer the separability and the higher the number of misclassified objects [49]. Thus, a minimum JeffryMatusita distance between two classes of approximately 1.5 is suitable to yield a limited number of misclassified objects [50].

Fig. 6 shows the separability (mean and standard deviation) for each signal feature and for each Irons \& Petersen textural feature.

\section{1) Separability between bare soils and forests}

At an incidence angle of $25^{\circ}$, the minimum Euclidian distance and variance of bare soils and forests show separabilities of greater than 1.5 under all soil moisture conditions (Fig. 6a). Moreover, when using the mean signal, the separability between bare soils and forests is above 1.5 $(\mathrm{J}>1.5)$ only for soil moistures above 25\% (March 17 and 26, 2009; May 11, 2009; March 2 and 4, 2010). At an incidence angle of $50^{\circ}$, the separability between bare soils and forests increases between March 18 and April 27, 2009 when using the signal standard deviation (leaves development) (Fig. 6a). Moreover, the standard deviation is greater than 1.5 for all images. The results also show that the mean signal provides high separability between bare soils and forests for soil moistures above $35 \%$ and below $15-20 \%$. The textural features of bare soils and forests have lower separability than their signal features. The Haralick textural features are above 1.5 only after April 20, 2009 (developed leaves) regardless of the incidence angle. The best features are GLCM correlation $0^{\circ}$, GLDV entropy $45^{\circ}$, and GLDV contrast in all directions.

\section{2) Separability between bare soils and crops}

At early crop growth stages (before April 17, 2009 and during the 2010 time series), the separability between bare soils and crops is greater when using the mean signal than when using the signal standard deviation or textural features, regardless of the TerraSAR-X configuration (incidence angle) or soil moisture conditions (Fig. 6b). The maximum separability between bare soils and crops (approximately 1.4) is observed when using the mean signal for soil moisture conditions above $35 \%$ at $50^{\circ}$ incidence angle (March 1, 2010) or for soil moisture contents above $25 \%$ at $25^{\circ}$ incidence angle (March 26 and April 8, 2009; March 2, 2010). For incidence angles of $25^{\circ}$ and $50^{\circ}$, the separability between bare soils and crops obtained using the mean signal decreases with decreased soil moisture (for example, between April 8 and 17, 2009 at $25^{\circ}$ and between March 25 and April 9, 2009 at 50 $)$. The presence of slaking crust on March 17 and 18, 2009, which generates signal variations at the bare plot scale due to soil moisture variation, results in a decrease of the separability between bare soils and crops.

The separability between bare soils and crops increases with the development of crops at incidence angles of both $25^{\circ}$ and $50^{\circ}$. When using the mean signal feature, the separability between bare soils and crops is greater than 1.5 (April 20, 27, and 28 and May 11, 2009) regardless of the soil moisture conditions. The best feature is the mean signal, but the minimum Euclidian distance and the variance give also good separabilities $(\mathrm{J}>1.5)$. When Haralick textural features are used, the separability between bare soils and crops is greater than 1.5 only when the crops are well developed. At both $25^{\circ}$ and $50^{\circ}$ incidence angles, the best features are GLCM contrast, GLCM dissimilarity, GLCM second moment, GLCM entropy, GLDV contrast, and GLDV mean (all directions). Finally, the separability between bare soils and crops is not influenced by the computation angle $\left(0^{\circ}, 45^{\circ}, 90^{\circ}, 135^{\circ}\right)$ (similar separability as with features all directions) when using Haralick texture.

In conclusion, bare soils and forests could be differentiated from TerraSAR-X data at $25^{\circ}$ incidence angle regardless of the soil moisture conditions by using the minimum Euclidian distance or the variance. At a $50^{\circ}$ incidence angle, the signal standard deviation is the best feature to use whatever the soil moisture conditions. To obtain a limited number of misclassified objects between bare soils and crops at early crop stages, the mean signal of TerraSAR-X data acquired in high soil moisture conditions (approximately 35\%) is required. Moreover, the separability between bare soils and developed crops obtained by using the mean signal feature is the highest regardless of the soil moisture conditions. Thus, although textural features have previously been shown to improve the SAR classification (X-band) of different crop types when crops are well developed [34], their potential to improve the discrimination of bare soils from crops appears limited. Moreover, the separability between bare soils and other landcover (forests and crops) does not improve the discrimination when two incidence angles are used instead of one.

\section{Operational TerraSAR-X soil moisture mapping}

The BSMOM dataset is used to test the applicability of a bare soil moisture mapping method (Table 1). This dataset permits monitoring of the temporal variations of soil moisture during a winter drying period of 13 days. It also permits the observation of the spatial variations of soil moisture both at the 'within-plot' and watershed scales.

\section{1) Bare soil mapping}

The first step in bare soil moisture mapping is to identify bare soils from the other landcover classes. Thus, the bare soil map should be obtained as soon as the beginning of the TerraSAR-X time series. Because the BSMOM TerraSAR-X dataset is acquired during early crop growth (March, 2010), bare soils mapping requires TerraSAR-X data acquired in wet soil moisture conditions, as demonstrated previously. Thus, a bare soils map is created from the first TerraSAR-X image (March 1, 2010; $\mathrm{HH}-50^{\circ}$ ) of the BSMOM dataset. Moreover, the soil moisture, which is approximately $36 \%$ at this stage, is optimal for differentiating bare soils from other landcover classes. An object-oriented approach based on segmentation 
and supervised classification is used to map bare soils based on the TerraSAR-X data of March 1, 2010.

\section{1) Segmentation of TerraSAR-X image}

To obtain the best bare soils object boundaries, the segmentation of the March 1, 2010 image is based on signal (backscattering coefficient) and minimum Euclidian distance. Indeed, for this TerraSAR-X acquisition, these two features are optimal to differentiate bare soils from forest and crops (Fig. 7). Because the signal has a greater separability value than the minimum Euclidian distance, a higher weight is assigned to the signal layer in the segmentation process. To improve the segmentation, the signal is filtered three times by a $7 \times 7$ Lee filter [51]-[52]-[53].

The visual evaluation of the segmentation quality of March 1, 2010 shows homogeneous and representative objects (Fig. 7). Compared to the results of optical segmentation, the TerraSAR-X segmentation results showed more ragged delineated segments. Well contrasted boundaries between landcover classes are correctly shaped by the segmentation, but the areas with low contrast are inaccurately shaped by the segmentation.

\section{2) Bare soil detection using TerraSAR-X images}

After segmentation, a supervised classification of each object is conducted to obtain a bare soils map for the BSMOM dataset. Several training objects representing bare soils, forests and crops are selected, and their signal values are computed. The backscattering coefficient feature is chosen because, as demonstrated previously, it is the best feature to use to differentiate bare soils from forests and crops. The optimal thresholds for differentiating bare soils from forests and crops are determined using the approach developed by [49]. The results show that bare soils are distinguished from forest by the condition $\sigma^{\circ}$ March $1,2010 \geq-10.8 \mathrm{~dB}$ and from crops by the condition $\sigma^{\circ}$ March $1,2010 \geq-8.8 \mathrm{~dB}$. Thus, bare soils can be distinguished from other landcover classes based on the condition $\sigma^{\circ}$ March 1,2010 $\geq-9 \mathrm{~dB}$. Above this threshold, all objects are classified as "bare soils"; below this threshold, all objects are classified as "other".

The validation of the March 1, 2010 bare soils map is performed in comparison to the reference bare soils map created from the RapidEye landcover map (Fig. 8). Both pixel and object-based confusion matrices are performed because these two methods do not lead to the same measure of accuracy. A pixel-based confusion matrix evaluates the global accuracy (influenced by boundary errors), whereas an objectbased confusion matrix measures the thematic accuracy and is only influenced by labeling error [54]. The pixel-based confusion matrix shows an overall accuracy of $84.6 \%$ and a kappa value of 0.65 , and the object-based confusion matrix shows an overall accuracy of $92.2 \%$ and a kappa value of 0.83 (Table 6). Thus, the bare soils map obtained using only a single configuration $\left(\mathrm{HH}-50^{\circ}\right)$ of TerraSAR-X has a good level of accuracy regardless of the confusion matrix sampling approach. The comparison made here between pixel- and object-based accuracies emphasizes the problem of ragged plot boundaries in the results obtained using the TerraSAR-X segmentation process.

Commission errors are imputed mainly to crop growth between the acquisition dates of RapidEye (May 26) and the TerraSAR-X image (March 1). Indeed, sprouting crops in March become developed crops in May. Because sprouting crops and bare soils cannot be differentiated using TerraSAR$\mathrm{X}$ signals, sprouting crops are classified as bare soils in the TerraSAR-X bare soils map (March 1). Consequently, some objects classified as crops in the RapidEye reference map were sprouting crops in March and were classified as bare soils in the TerraSAR-X classification.

An unsupervised object classification (Isodata: 3 classes and 6 iterations) based on the TerraSAR-X segmentation and a supervised object classification using digitalized object boundaries were also evaluated and compared to the previously described classifications (TerraSAR-X segmentation and supervised classification). Although the overall object-based accuracies are similar (between $92 \%$ and 94\%) (Table 7), the overall pixel-based accuracy of the supervised classification using digitalized object boundaries is considerably higher $(94 \%)$ than that of other methods of classification using TerraSAR-X segmentation (85\%) (Table 7). Indeed, digitalized object boundaries overcome the error of segmentation (no ragged boundaries); consequently, there are no misclassifications of the boundary pixels. Moreover, only a short processing time is needed for unsupervised classification. Thus, unsupervised object classification could be sufficient to detect bare soils with good accuracy in an operational process of soil moisture estimation.

\section{2) Bare soil moisture mapping}

For each TerraSAR-X image of the BSMOM dataset (Table $1)$, the mean backscattering coefficient is calculated for each bare soil object detected on the March 1, 2010 TerraSAR-X image. The same bare soils map is used throughout the TerraSAR-X time series because the BSMOM dataset covers a short winter time period (13 days) during which the landcover change is assumed to be negligible. A window size of $7 \times 7$ pixels was used to compute the backscattering coefficient from the acquired TerraSAR-X images. Indeed, this window size results in reduction of speckle noise and retains the high resolution of TerraSAR-X data necessary to observe 'withinplot' soil moisture variations [19]. Subsequently, for each TerraSAR-X image, the relationship $\sigma^{\circ} \mathrm{dB}(\mathrm{mv})$ corresponding to the same radar configuration (incidence) was used to invert the backscattered signal into soil moisture. A flowchart depicting the bare soil moisture mapping method is presented in Fig. 9.

Fig. 10 shows the results of bare soils moisture mapping of the BSMOM dataset; this data allows the investigator to monitor the temporal variations in soil moisture during a winter drying period of 13 days. At the beginning of the TerraSAR-X time series acquired in 2010, the average estimate of soil moisture on the watershed is approximately $36 \%($ standard deviation $=11.1 \%)$ for March 1, $2010($ Fig. 10, 
and Table 8). The mean soil moisture then decreases to $27.8 \%$ on March 4, in accordance with the lack of precipitation and an air temperature between $0^{\circ} \mathrm{C}$ and $10.6^{\circ} \mathrm{C}$ (Table 8).

On March 5, the moisture content estimate for the watershed is approximately $17.7 \%$. The marked decrease in soil moisture that occurs between March 4 and March 5 (-10\% in only one day) is not in accordance with the decrease shown by in situ measurements $(-1.2 \%)$. Indeed, the TerraSAR-X image was acquired at $05 \mathrm{~h} 52$ (UTC) at a minimal air temperature of approximately $2.5^{\circ} \mathrm{C}$. The low ambient temperature resulted in the freezing of a portion of the liquid water in the soil and caused a significant decrease in the microwave signal due to the difference in the dielectric properties of liquid and solid water [55]. Thus, the low backscattered signal on March 5 produced a lower soil moisture estimate because the soil content of liquid water is small (ice crystals are present in the pores of the soil). Thus, the relationship between the radar signal and the soil moisture developed in this paper is not applicable in cases of frozen soils. In the C-band, a decrease of $-3 \mathrm{~dB}$ to $-5 \mathrm{~dB}$ in the backscattered signal has already been observed for freezing soil [56]-[57]-[58].

The lack of precipitation between March 5 and March 10 explains the decrease in in situ soil moisture measurements on March 10 (20\% vs. 30.4\% on March 5). The estimated moisture content estimated from TerraSAR-X images also decreases between March 5 and March 10 (12.2\% on March 10 vs. $17.7 \%$ on March 5). Nevertheless, the soil moisture estimate obtained using TerraSAR-X images is underestimated, and the decrease in soil moisture is less $(\sim$ $5.5 \%)$ than that observed in situ $(\sim-10.4 \%)$. This difference can be explained by the frozen condition of the soil (the minimum air temperature between March 5 and March 10 was approximately $-3^{\circ} \mathrm{C}$, and the images were acquired during the early morning). This is an important consideration when the imaged soil is frozen because the TerraSAR-X signal is only sensitive to liquid water, whereas gravimetric measurements integrate all water content.

Between March 10 and March 12, the minimal air temperature remained around $-3^{\circ} \mathrm{C}$. In situ measurements show a slight decrease in soil moisture between March 10 and 12 (20\% and $18 \%$, respectively), whereas the estimated soil moisture increases slightly between these two dates $(12.2 \%$ and $14.7 \%$, respectively). The observed increase in soil moisture in the absence of rain is explained by the effect of frozen soil on the SAR signal. Indeed, on March 10, the TerraSAR-X signal, which was acquired at 06h47 UTC, measures only the liquid water, whereas on March 12 the TerraSAR-X signal acquired at $17 \mathrm{~h} 43$ UTC measures both the soil liquid water of March 10 and the portion of the total water that thawed during the day on March 12. Thus, the amount of liquid water in the soil is greater on March 12 than on March 10 , and the TerraSAR-X sensor measures an increase in soil moisture despite the fact that the gravimetric measurements show a decrease in soil moisture due to lack of precipitation and soil drying.

In a similar manner, the soil moisture estimated using the
TerraSAR-X data increases from $14.7 \%$ to $17.5 \%$ between March 12 and 13, whereas the soil moisture measured in situ remains constant $(\sim 18.5 \%)$. The increase in the soil moisture estimate is consistent with the thawing of the soil; such thawing engenders a decrease in the amount of ice crystals in the macroporosity and an increase in the amount of liquid water in the soil (the radar image was acquired at $17 \mathrm{~h} 26$ UTC at an air temperature above $0^{\circ} \mathrm{C}$ ).

The presence of slaking crust on some bare soil plots leads to within-plot variations in the soil moisture on March 4, 12 and 13 (Fig. 10). Reference [19] have shown, using data obtained in winter 2009, that the soils on this watershed consist of two loamy soils, one of which is sensitive to slaking crust formation on the topsoil layer (16\% clay, $78 \%$ silt, and $6 \%$ sand) and one that is without slaking crust ( $24 \%$ clay, $71 \%$ silt, and 5\% sand). Their results show that crusted soils (CS) have greater soil moisture than soils without crusts (SWC). Indeed, slaking crusts are resistant to water infiltration and favor hydric inertia; consequently, soil moisture content is retained longer in soils covered by crusts than in soils without crusts [19].

At the beginning of the TerraSAR-X time series (March 1 and 2), there was no difference in the soil moisture estimates for SC and SWC soils (below 1.5\%). The in situ difference in soil moisture between the two types of soil was of the same order of magnitude (below 4\%) in comparison to the TerraSAR-X radiometric precision $(1 \mathrm{~dB})$. For these dates, no variation in soil moisture was observed within the plots because the previous rainy events $(19.4 \mathrm{~mm}$ between February 25 and March 1) balanced the difference in soil moisture between the two soil structures. Slight variations in soil moisture within plots are detected on March 4 (difference in soil moistures approximately $3.7 \%$ between SC and SWC) (Fig. 10). Indeed, during the dry period that occurred between March 2 and 4, the soil moisture of SC remains constant because the crust of this soil limits water evaporation; during the same period, the soil moisture of SWC decreases due to evaporation. Consequently, the difference in soil moisture between the two soils structure increases (7.8\%).

On March 5 and 10 (data acquired approximately 6 h UTC), no difference in the soil moisture estimates for SC and SWC obtained using TerraSAR-X was observed (below 1\%), whereas the gravimetric measurements show a difference in soil moisture greater than $10 \%$. Because the soils were frozen on these two acquisition dates, the difference in the moisture content estimates of the two soils is likely due to the slight difference in liquid water content of SC and SWC, whereas the gravimetric measurements represent the total water content (solid and liquid) of the two soils.

On March 12 and 13 (acquired approximately 17h30 UTC), within-plot variations in soil moisture are clearly discernible on the TerraSAR-X bare soils moisture maps. Indeed, on March 12, the two soil structures have begun to thaw, and the difference in the soil moisture estimates between SC and SWC $(9.7 \%)$ are in accordance with those measured in situ (12.5\%) (Fig. 10). Nevertheless, the SCs with high soil moisture cover a greater area on March 13 than on March 12 because some 
areas of SC are still frozen on March 12 but have thawed on March 13. The SC areas that thawed later show an increase in soil moisture of about $+7 \%$ between March 12 and 13 (without rainy events), whereas the other areas have constant soil moisture (only $+1.3 \%$ between March 12 and 13). Thus, slaking crust slows the thawing of soil because the crust on the topsoil layer limits heat exchange between the soil and the atmosphere (i.e., it limits soil warming).

Finally, some plots do not show soil moisture variations at the within-plot level on the March 12 and 13 images. These plots correspond to recently ploughed plots. Indeed, because tillage operations destroyed the soil crust, no variation in soil moisture, either measured or estimated, was observed within these plots.

To conclude, the bare soils moisture map time series of 2010 clearly illustrates the difference in hydric processes between crusted (SC) and non-crusted (SWC) soils under the conditions of a winter dry period (March 1 to 13, 2010). In cases where freezing occurred, no difference in soil moisture estimates made using TerraSAR-X data was observed between the two soil structures. In cases in which thawing occurs, the crusted soils are less sensitive to thawing than the soils without crust. Thus, SC required more time than SWC to thaw fully. Moreover, bare soils moisture maps that show withinplot variations in soil moisture can be used to derive other products, such as slaking crust extent maps or recently ploughed plots maps.

\section{CONCLUSIONS AND PERSPECTIVES}

This study proposes a methodology to exploit TerraSAR-X images in an operational process of bare soils moisture mapping. The mapping process uses only mono-configuration TerraSAR-X data (incidence angle, polarization) both for bare soils detection and for the estimation of soil moisture content.

The empirical relationships between the bare soils moisture content and the TerraSAR-X signal acquired at different SAR configurations were first developed using a training database of 182 bare plots. The validation of these relationships was performed using a second database acquired over four study sites (121 plots). The results show that, regardless of the TerraSAR-X configuration and the soil surface conditions (roughness and soil composition), the Root Mean Square Error of the soil moisture estimate is less than $4 \%$. Thus, TerraSAR$\mathrm{X}$ sensor data can be used to develop soil moisture operational products over an extremely wide range of agricultural soil surface conditions for soil compositions ranging from loamy to sandy clay, for soils with or without slaking crust, and for soils with surface roughness ranging from that present at sowing (smooth) to that present during winter plowing (rough).

In this work, the differentiation of bare soils from other landcover classes was analyzed using the TerraSAR-X mean signal (backscattering coefficient) and the same textural features that are often used in SAR studies to improve discrimination between landcover classes. The results show that the potential of TerraSAR-X data to differentiate bare soils from other classes is influenced mainly by crop growth and the soil moisture conditions regardless of the TerraSAR-X incidence angle. Indeed, when crops are fully developed, it is always possible to detect bare soils from crops, regardless of the soil moisture content, and the mean signal provides better separability than the textural features. Nevertheless, at early crop growth stages, bare soils detection can only be performed using the mean signal acquired under wet conditions.

The process of retrieving bare soils moisture from TerraSAR-X data has been applied using a time series acquired at an early crop stage (winter). In this study, bare soils mapping was conducted without optical data and using only the first TerraSAR-X data of the time series. An objectbased classification was used to create the bare soils map. In the segmentation process using the TerraSAR-X image, the bare object boundaries were well defined by the minimum Euclidian distance and mean signal features. Supervised and unsupervised classifications using only the mean signal of segmented objects provides bare soils maps with overall accuracies based on objects of approximately $92 \%$. The overall accuracies of bare soils maps of the same areas based on pixels decreased to $84 \%$ because of misclassified pixels present in the ragged object boundaries created by the TerraSAR-X segmentation. The overall accuracy based on pixels can be improved by using digitalized plot boundaries instead of TerraSAR-X segmentation (94\%). The estimation of soil moisture was performed on each image of the TerraSAR-X time series using the bare soil map and the relationships developed previously; the results showed that TerraSAR-X sensor data can be used to accurately estimate soil moisture and to monitor soil moisture variations at the within-plot scale.

The proposed methodology can provide the bare soils hydric state of a specified agricultural area with a short processing time of a few hours after image reception. Moreover, TerraSAR-X bare soil moisture maps could be used to derive other useful products for environmental studies, such as slaking crust maps (erosion and agriculture) and soil freezing maps (climate change studies). Finally, the high periodicity of the TerraSAR-X sensor ( $\sim 1$ day) permits acquiring soil moisture maps at time scales suitable for hydrologic process monitoring. Future work will address the use of the TerraSAR-X soil moisture maps described here as input for the development of hydrological models.

\section{ACKNOWLEDGMENT}

The authors wish to thank the staff of IRSTEA (P. Ansart, E. Gonzales-Sosa, C. Loumagne, R. Meloni, G. Tallec) and that of INRA/AgroParisTech (J.M. Gilliot, N. Saint-Geours) for their knowledge and help during the field studies.

\section{REFERENCES}

[1] F. Herbert, "Dune", ed. Robert Laffont, coll. Pocket science-fiction, 1965 (ISBN 2-226-11403-4). 
[2] J.P. Walker, "Estimating soil moisture profile dynamics from nearsurface soil moisture measurements and standard meteorological data" The University of Newcastle, 1999.

[3] Q. Wu, M. Wang, "A framework for risk assessment on soil erosion by water using an integrated and systematic approach", Journal of Hydrology, 337(1-2), 2007, pp.11-21.

[4] O. Cerdan, J. Poesen, G. Govers, N. Saby, Y. Le Bissonnais, A. Gobin, A. Vacca, J. Quinton, K. Auerswald, A. Klik, F.J.P.M. Kwaad, M.J. Roxo, "Sheet and rill erosion rates in Europe. In Soil Erosion in Europe", chap. 38, 2006, pp.501-513.

[5] Y.H. Kerr, P. Waldteufel, J.P. Wigneron, J. Martinuzzi, J. Font, M. Berger, M., "Soil moisture retrieval from space: the Soil Moisture and Ocean Salinity (SMOS) mission", IEEE Transactions on Geoscience and Remote Sensing, 39(8), 2001, pp.1729-1735.

[6] W. Wagner, G. Lemoine, H. Rott, "A Method for Estimating Soil Moisture from ERS Scatterometer and Soil Data", Remote Sensing of Environment, 70(2), 1999, pp.191-207.

[7] Z. Bartalis, W. Wagner, V. Naeimi, S. Hasenauer, K. Scipal, H., Bonekamp, J. Figa, C. Anderson, "Initial soil moisture retrievals from the METOP-A Advanced Scatterometer (ASCAT)", Geophysical Research Letters, 34(20), 2007, p.L20401.

[8] N. Baghdadi, O. Cerdan, M. Zribi, V. Auzet, F. Darboux, M. El Hajj, "Operational performance of current synthetic aperture radar sensors in mapping soil surface characteristics in agricultural environments: application to hydrological and erosion modelling", Hydrological Processes, 22(1), 2008, pp.9-20.

[9] S. Le Hegarat-Mascle, M. Zribi, F. Alem, A. Weisse, C. Loumagne, "Soil moisture estimation from ERS/SAR data: toward an operational methodology", IEEE Transactions on Geoscience and Remote Sensing, 40(12), 2002, pp.2647-2658.

[10] M. Zribi, M. Dechambre, "A new empirical model to retrieve soil moisture and roughness from C-band radar data", Remote Sensing of Environment, 84(1), 2002, pp.42-52.

[11] B.W Barrett, E. Dwyer, P. Whelan, "Soil moisture retrieval from active spaceborne microwave observations: An evaluation of current techniques", Remote Sensing, 1(3), 2009, pp.210-242.

[12] M.C. Dobson, F.T. Ulaby, L.E. Pierce, "Land-cover classification and estimation of terrain attributes using synthetic aperture radar", Remote Sensing of Environment, 51(1), 1995, pp.199-214.

[13] F.T. Ulaby, F. Kouyate, B. Brisco, T.H.L. Williams, "Textural Infornation in SAR Images", IEEE Transactions on Geoscience and Remote Sensing, GE-24(2), 1986, pp.235-245.

[14] A.K. Fung, "Microwave Scattering and Emission Models and their Applications", Artech House, Norwood, Massachussett, 1994, 573 p.

[15] N. Baghdadi, M. Aubert, O. Cerdan, L. Franchistéguy, C. Viel, E. Martin,"Operational Mapping of Soil Moisture Using Synthetic Aperture Radar Data: Application to the Touch Basin (France)", Sensors, 7(10), 2007, pp.2458-2483.

[16] Y. Oh, K. Sarabandi, F.Y. Ulaby, "An empirical model and an inversion technique for radar scattering from bare soil surfaces", IEEE Transactions on Geoscience and Remote Sensing, 30(2), 1992, pp.370381.

[17] F.T. Ulaby, P.P. Batlivala, M.C. Dobson, "Microwave Backscatter Dependence on Surface Roughness, Soil Moisture, and Soil Texture: Part I-Bare Soil", IEEE Transactions on Geoscience Electronics, 16(4), 1978, pp.286-295.

[18] M. Zribi, A. Chahbi, M. Shabou, Z. Lili-Chabaane, B. Duchemin, N. Baghdadi, R. Amri, A. Chehbouni, "Soil surface moisture estimation over a semi-arid region using ENVISAT ASAR radar data for soil evaporation evaluation", Hydrology Earth System Science, 15(1), 2011, pp.345-358.

[19] M. Aubert, N. Baghdadi, M. Zribi, A. Douaoui, C. Loumagne, F. Baup, M. El Hajj, and S. Garrigues, "Analysis of TerraSAR-X data sensitivity to bare soil moisture, roughness, composition and soil crust", Remote Sensing of Environment, 115, 2011, pp.1801-1810.

[20] R. Prakash, D. Singh, N.P. Pathak, "Microwave specular scattering response of soil texture at X-band", Advances in Space Research, 44(7), 2009, pp.801-814.

[21] N. Baghdadi, N. Holah, M. Zribi, "Soil moisture estimation using multiincidence and multi-polarization ASAR data", International Journal of Remote Sensing, 27(10), 2006, pp.1907-1920.

[22] H.S. Srivastava, P. Patel, M.L. Manchanda, S. Adiga, "Use of multiincidence angle RADARSAT-1 SAR data to incorporate the effect of surface roughness in soil moisture estimation", IEEE Transactions on Geoscience and Remote Sensing, 41(7), 2003, pp.1638- 1640.
[23] N. Baghdadi, M. Aubert, M. Zribi, "Use of TerraSAR-X Data to Retrieve Soil Moisture Over Bare Soil Agricultural Fields", IEEE Geoscience and Remote Sensing Letters, PP(99), 2011, pp.1-5.

[24] N. Baghdadi, P. Camus, N. Beaugendre, O.M. Issa, M. Zribi, J.F. Desprats, J.L. Rajot, C. Abdallah, C. Sannier, "Estimating Surface Soil Moisture from TerraSAR-X Data over Two Small Catchments in the Sahelian Part of Western Niger", Remote Sensing, 3, 2011b, pp.12661283.

[25] P.C., Dubois, J. Van Zyl, T. Engman, "Measuring soil moisture with imaging radars", IEEE Transactions on Geoscience and Remote Sensing, 33(4), 1995, pp.915-926.

[26] F.T., Ulaby, P.C. Dubois, J. Van Zyl, "Radar mapping of surface soil moisture", Journal of Hydrology, 184 (1-2), 1996, pp: 57-84.

[27] R. Prakash, D. Singh, N.P. Pathak,, "A Fusion approach to retrieve soil moisture with SAR and optical data", IEEE Journal of Selected Topics in Applied Earth Observations and Remote Sensing, PP (99), 2011, pp.111 .

[28] N. Baghdadi, R. Cresson, P. Todoroff, S. Moinet, "Multitemporal Observations of Sugarcane by TerraSAR-X Images", Sensors, 10(10), 2010, pp.8899-8919.

[29] M. Mroz, M. Mleczko, "Potential of TerraSAR-X data in early and rapid agricultural crops mapping. TerraSAR-X", Science team Meeting, DLR, Oberpfaffenhofen conference, 2008.

[30] J. Breidenbach, S.M. Ortiz, M. Reich, "Forest monitoring with TerraSAR-X: first results", European Journal of Forest Research, 129(5), 2010, pp.813-823.

[31] H. Anys, \& H. Dong-Chen, "Evaluation of textural and multipolarization radar features for crop classification", IEEE Transactions on Geoscience and Remote Sensing, 33(5), 1995, pp.1170-1181.

[32] T. Kurosu, S. Uratsuka, H. Maeno, T. Kozu, "Texture statistics for classification of land use with multitemporal JERS-1 SAR single-look imagery", IEEE Transactions on Geoscience and Remote Sensing, 37(1), 1999, pp.227-235.

[33] J.V. Soares, C.D. Rennó, A.R. Formaggio, C. da Costa Freitas Yanasse, A.C. Frery, "An investigation of the selection of texture features for crop discrimination using SAR imagery", Remote Sensing of Environment, 59(2), 1997, pp.234-247.

[34] A. Mahmoud, S. Elbialy, B. Pradhan, M. Buchroithner, "Field-based landcover classification using TerraSAR-X texture analysis", Advances in Space Research, 48(5), 2011, pp.799-805.

[35] A.M. Dean, G.M. Smith, "An evaluation of per-parcel land cover mapping using maximum likelihood class probabilities", International Journal of Remote Sensing, 24(14), 2003, pp.2905-2920.

[36] J. Boiffin, F. Papy, M. Eimberck, "Influence des systèmes de culture sur les risques d'érosion par ruissellement concentré: Analyse des conditions de déclenchement de l'erosion", 1988.

[37] M. Eimberck, "Facteurs d'érodibilité des sols limoneux: Reflexions a partir du cas du Pays de Caux", Cah. Ortom, Ser. Pedol., 25(1-2), 1990, pp.81-94.

[38] M. Eineder, T. Fritz, "TerraSAR-X Ground Segment Basic Product Specification Document", Doc.: TX-GS-DD-3302; DLR: Wessling, Germany, 18 March 2009; Issue 1.6, p. 108. Available online: https://tandemx-science.dlr.de/pdfs/TX-GS-DD-3302 Basic-ProductsSpecification-Document V1.6.pdf, 2009.

[39] T. Le Toan, P. Smacchia, J.C. Souyris, A. Beaudoin, M. Merdas, M. Wooding, J. Lichteneger, "On the retrieval of soil moisture from ERS-1 SAR data", in Proceedings Second ERS-1 Symposium. Space at the Servive of our Environment,11-14 October 1993. Hamburg, Germany, 1994, pp. 883-888

[40] M. Zribi, N. Baghdadi, N. Holah, O. Fafin, "New methodology for soil surface moisture estimation and its application to ENVISAT-ASAR multi-incidence data inversion", Remote Sensing of Environment, 96(34), 2005, pp.485-496.

[41] A. Weimann, M. Von Schonermark, A. Schumann, P. Jorn, R. Gunther, "Soil moisture estimation with ERS-1 SAR data in the East-German loess soil area", International Journal of Remote Sensing, 19(2), 1998, pp.237-243.

[42] J. Sokol, H. NcNairn, T.J. Pultz, "Case studies demonstrating the hydrological applications of C-band multipolarized and polarimetric SAR", Canadian Journal of Remote Sensing, 30:(3) 2004, pp.470-483

[43] A. Beaudoin, Q.H.J. Gwy, T. Le Toan, "SAR observation and modelling of the C-band backscatter variability due to multi-scale geometry and soil moisture", IEEE Transactions on Geoscience \& Remote Sensing, vol. $28,1990,886-894$. 
[44] B.A.M. Bouman, "Crop parameter estimation from ground-based x-band (3-cm wave) radar backscattering data", Remote Sensing of Environment, 37(3), 1991, pp.193-205.

[45] G. Cookmartin, P. Saich, S. Quegan, R. Cordey, P. Burgess-Allen, A. Sowter, "Modeling microwave interactions with crops and comparison with ERS-2 SAR observations", IEEE Transactions on Geoscience and Remote Sensing, 38(2), 2000, pp.658-670.

[46] J.R. Irons, G.W. Petersen, "Texture transforms of remote sensing data", Remote Sensing of Environment, 11, 1981, pp.359-370.

[47] R.M. Haralick, K. Shanmugam, I.H. Dinstein, "Textural features for image classification", Systems, Man and Cybernetics, IEEE Transactions on, 3(6), 1973, pp.610-621.

[48] A. Bhattacharyya, "On a measure of divergence between two statistical populations defined by their probability distributions", Bulletin of the Calcutta Mathematical Society,35,1943, 1943, pp: 99-109.

[49] S. Nussbaum, I. Niemeyer, M.J. Canty, "SEATH-a new tool for automated feature extraction in the context of object-based image analysis", Proc 1st International Conference on Object-based Image Analysis (OBIA 2006), ISPRS, Volume 36, 2006.

[50] C.G.J. Schotten, W.W.L. Van Rooy, L.L.F. Janssen, "Assessment of the capabilities of multi-temporal ERS-1 SAR data to discriminate between agricultural crops", International Journal of Remote Sensing, vol. 16, issue 14., 1995, pp:2619-2637.

[51] J.S. Lee, M. Grunes, E. Pottier, L. Ferro-Famil, "Segmentation of polarimetric SAR images", IGARSS Proceding of Geoscience and Remote sensing, 9-13, July 2001, Sydney, Australia, vol. 1, 2001, pp:414-416.

[52] M. Dabboor, V. Karathanassi, A. Braun, "A multi-level segmentation methodology for dual-polarized SAR data", International Journal of Applied Earth Observation and Geoinformation, 2011.

53] G. De Grandi, D. Hoekman, J.S. Lee, D. Schuler, T. Ainsworth, " A wavelet multiresolution technique for polarimetric texture analysis and segmentation of SAR images", Geoscience and Remote Sensing Symposium, 2004. IGARSS '04. Proceedings. 2004 IEEE International.

[54] J. Radoux, P. Defourny, P. Bogaert, "Comparison of pixel-and objectbased sampling strategies for thematic accuracy assessment", GEOBIA 2008 - Pixels, Objects, Intelligence, August 5-8, 2008, Calgary, Alberta, Canada, Volume XXXVIII-4/C1, 2008.

[55] U. Wegmüller, "The effect of freezing and thawing on the microwave signatures of bare soil", Remote Sensing of Environment, 33(2), 1990, pp.123-135.

[56] E.J. Rignot, J.J. Van Zyl, "Change detection techniques for ERS-1 SAR data", IEEE Transactions on Geoscience and Remote Sensing, 31(4), 1993, pp.896-906.

[57] J.D. Villasensor, D.R. Fatland, L.D. Hinzman, "Change detection on Alaska's North Slope using repeat-pass ERS-1 SAR images", IEEE Transactions on Geoscience and Remote Sensing, 31(1), 1993, pp.227236.

[58] J. Way, R. Zimmermann, E. Rignot, K. McDonald, R. Oren, "Winter and spring thaw as observed with imaging radar at BOREAS", Journal of Geophysical Research, 102(D24), 1997, pp. 29,673-29,684 


\section{Figures}

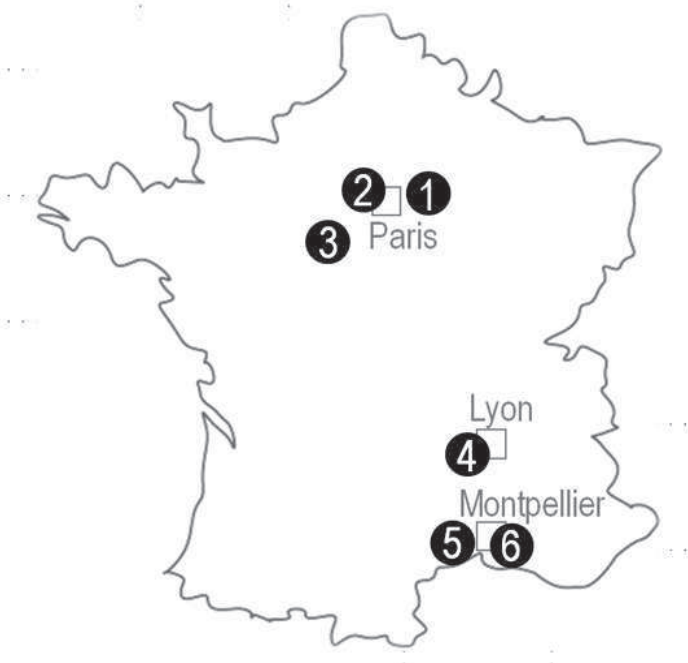

Fig. 1. Locations of study sites: Orgeval (1), Versailles (2), Villamblain (3), Yzeron (4), Thau (5), and Garon (6).
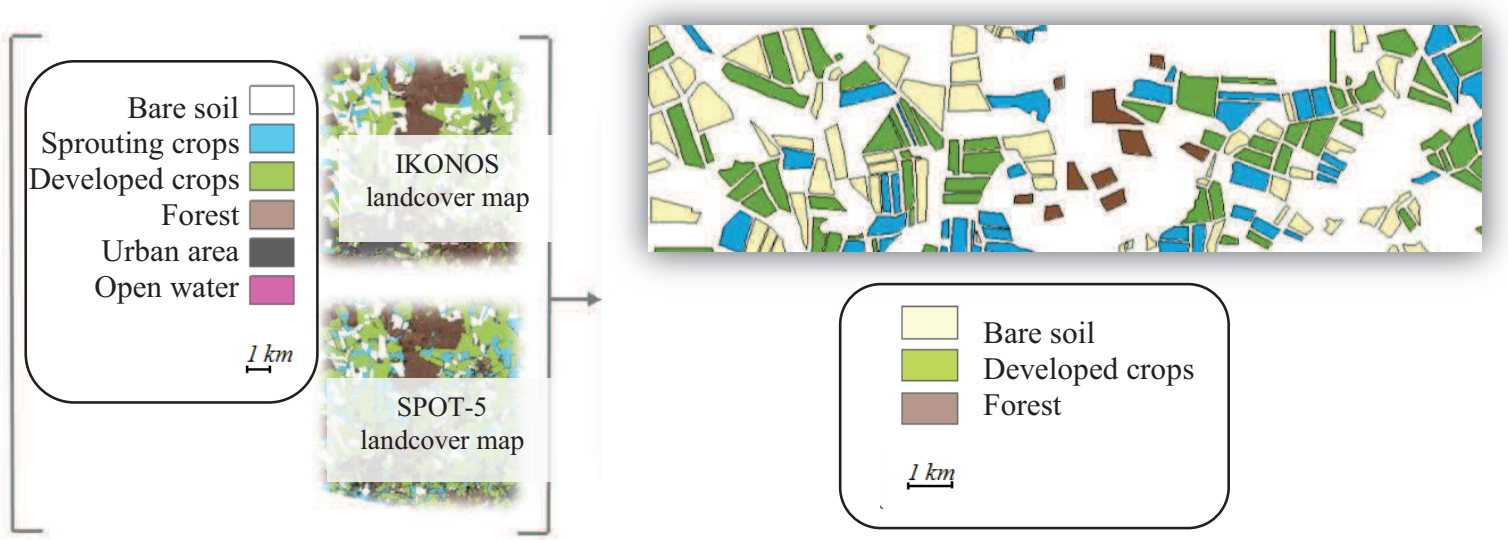

Fig. 2. Process used in creating training plots for the period March to May 2009 (Orgeval) 
(a) $\mathrm{HH}-25^{\circ}, \mathrm{VV}-33^{\circ}$

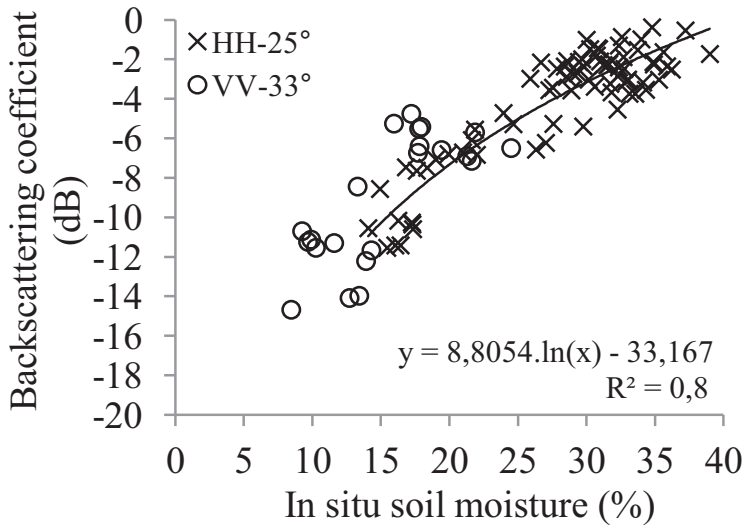

(b) $\mathrm{HH}-50^{\circ}, \mathrm{VV}-54^{\circ}$

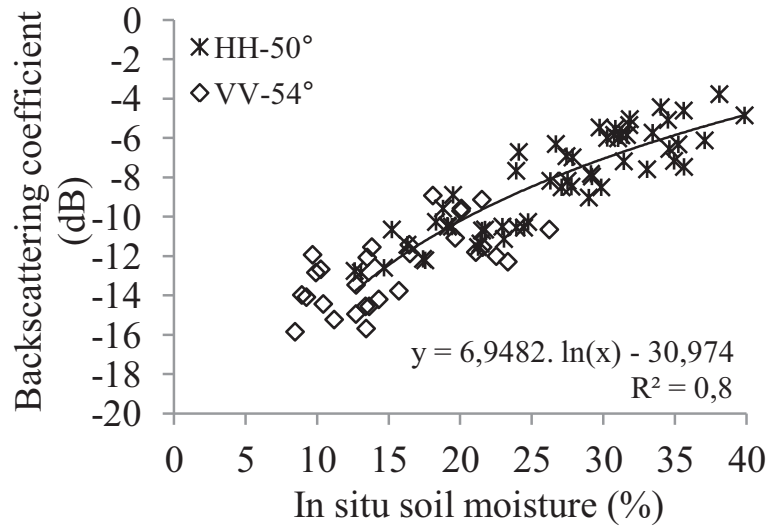

Fig. 3. Sensitivity of TerraSAR-X signals to surface soil moisture (SMAC dataset) for HH and VV polarization acquired with incidence angles from 25 to $33^{\circ}$ (a) and from 50 to $54^{\circ}$ (b). Each point corresponds to the average backscattering coefficient for one training plot.

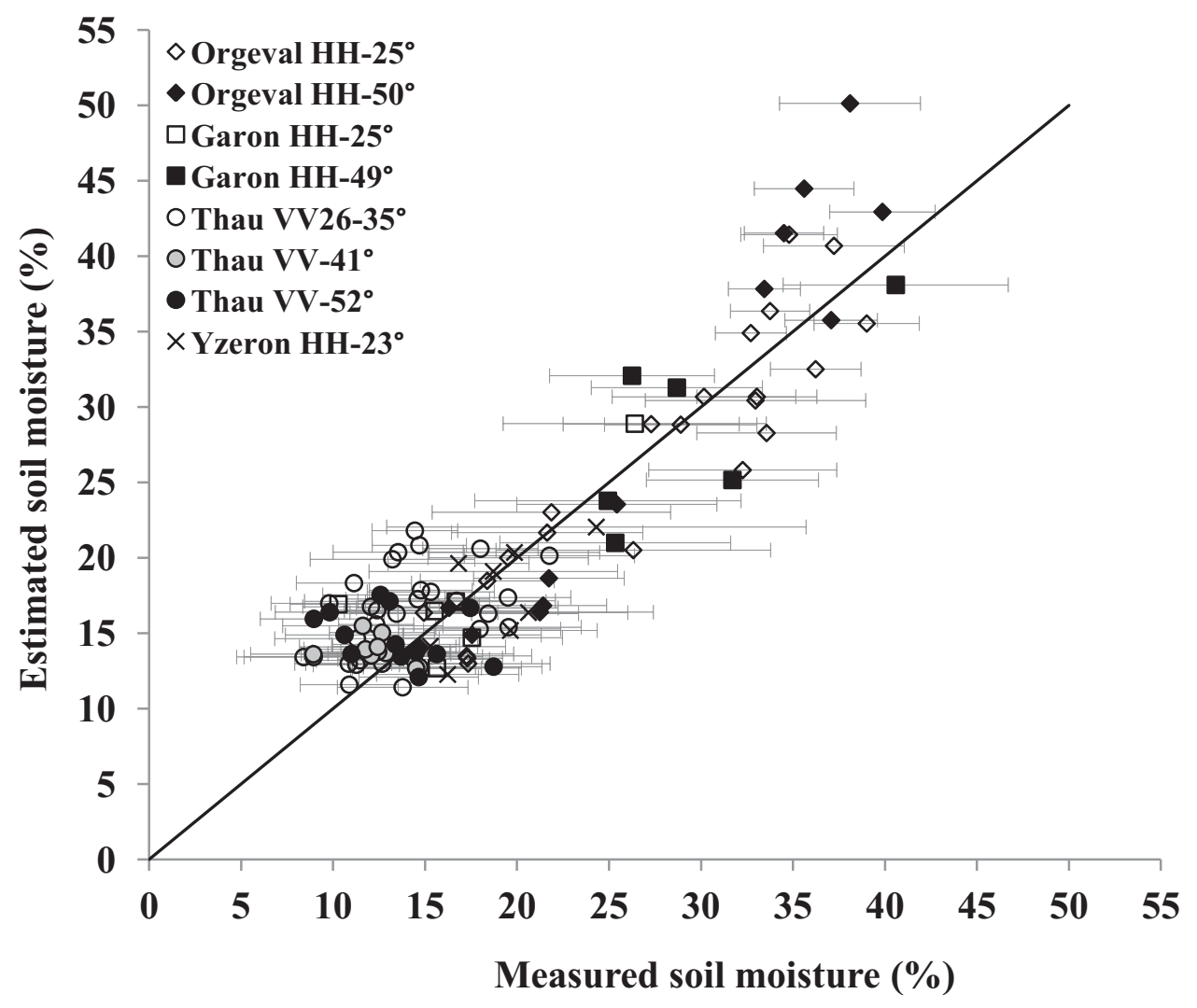

Fig. 4. Comparison between soil moisture estimates made using TerraSAR-X data and in situ soil moisture measurements at the training-plot scale. The SMAV dataset was used. For 95\% of the training plots, the standard deviation of the in situ soil moisture measurements at the plot scale varied between 2.0 and $7.1 \%$ (mean=3.8\%). 

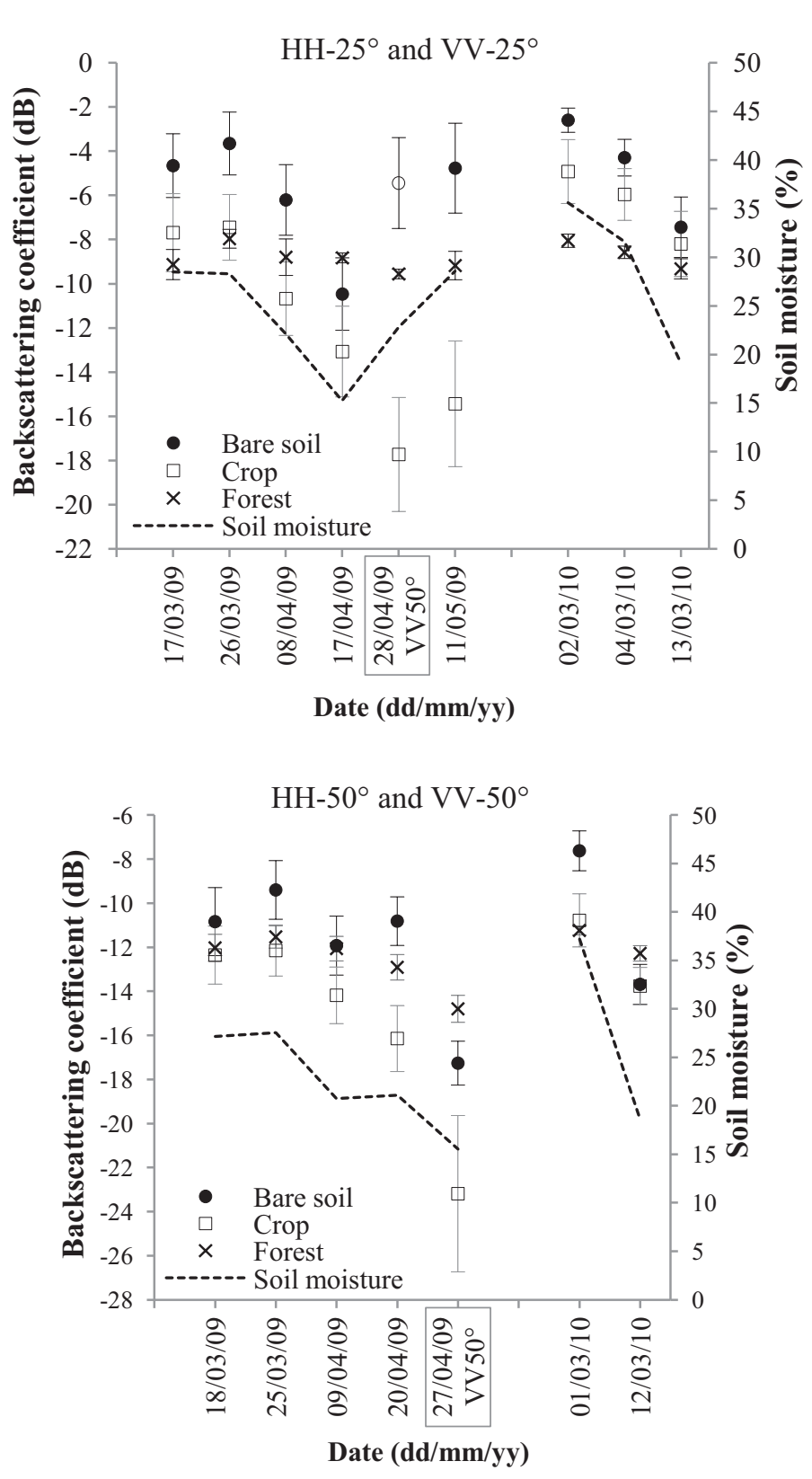

Fig. 5. TerraSAR-X backscattered signal for each landcover class of the BSD dataset (2009 and 2010). In situ soil moisture is also plotted. Bars correspond to the standard deviation of the TerraSAR$X$ signal obtained using all training plots of each landcover class. 
(a) Bare soils - Forests

HH-25 ${ }^{\circ}, V^{-25}{ }^{\circ}$
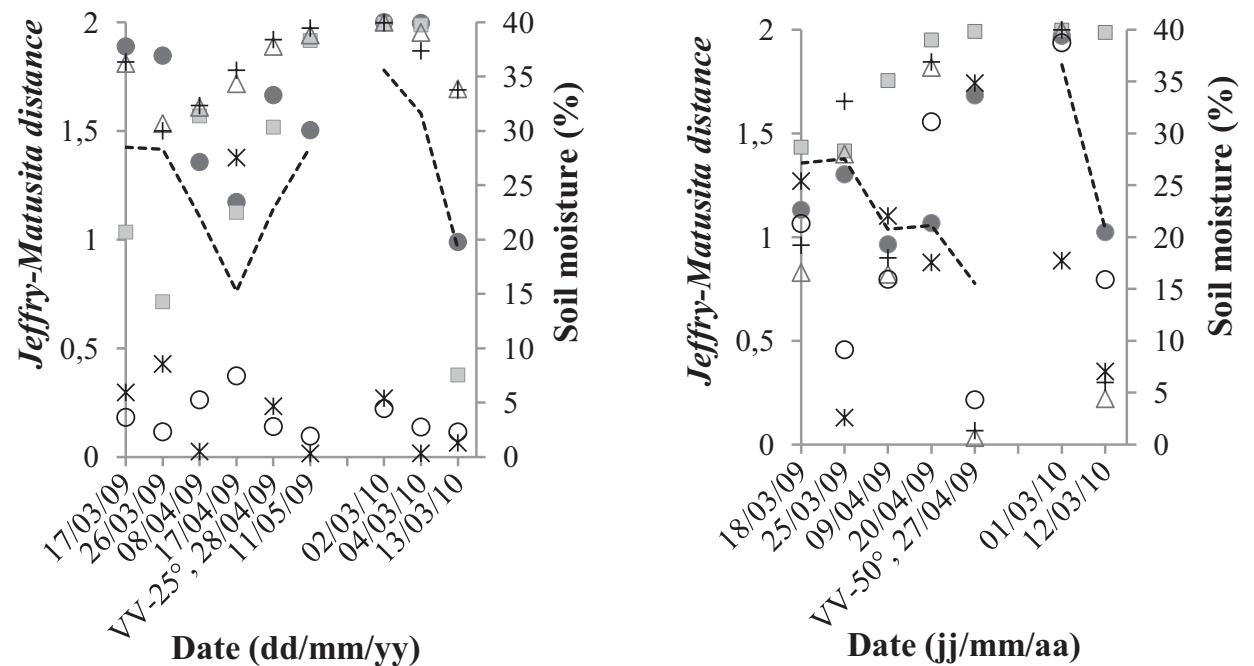

(b) Bare soils - Crops
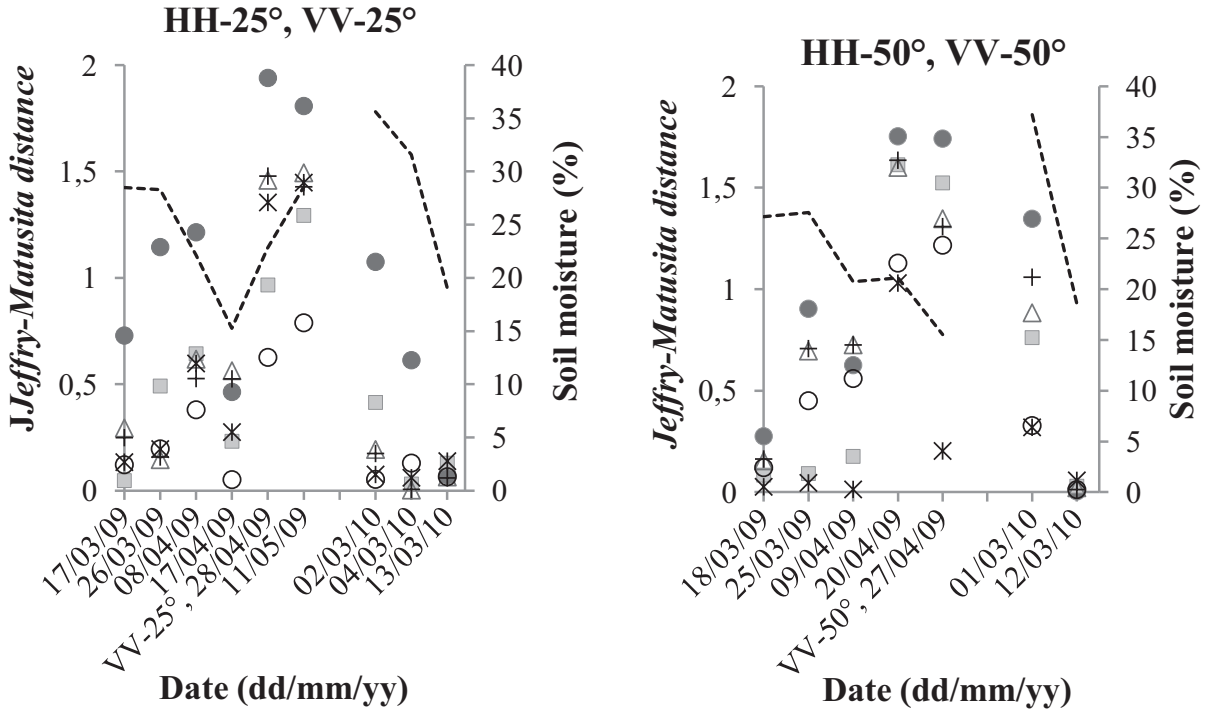

- Mean signal

$\triangle$ Variance

+ Minimum Euclidian distance Soil moisture

$\diamond \quad$ Signal standard deviation

- Skewness

* Kurtosis

Fig. 6. Temporal variation of Jeffry-Matusita distance (J) for each signal and texture features. 


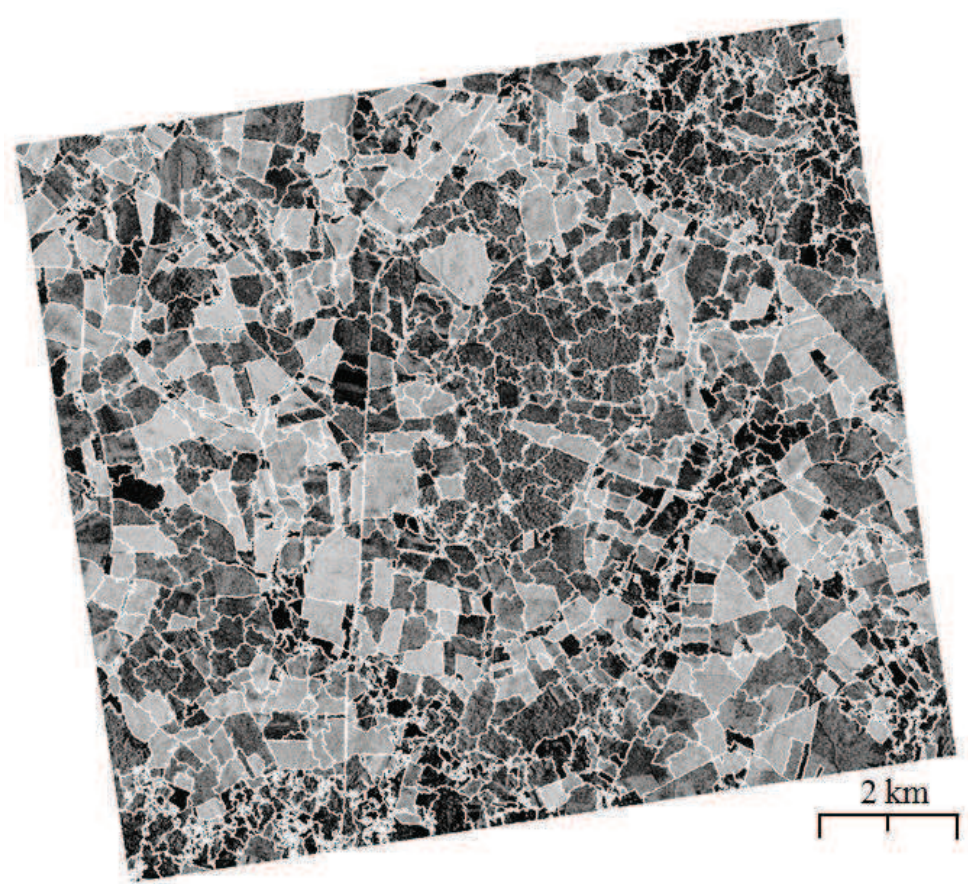

Fig. 7. March 1, 2010 TerraSAR-X segmentation. Central coordinates: lat. $48^{\circ} 51^{\prime} \mathrm{N}$ and long. $3^{\circ} 07^{\prime} \mathrm{E}$.

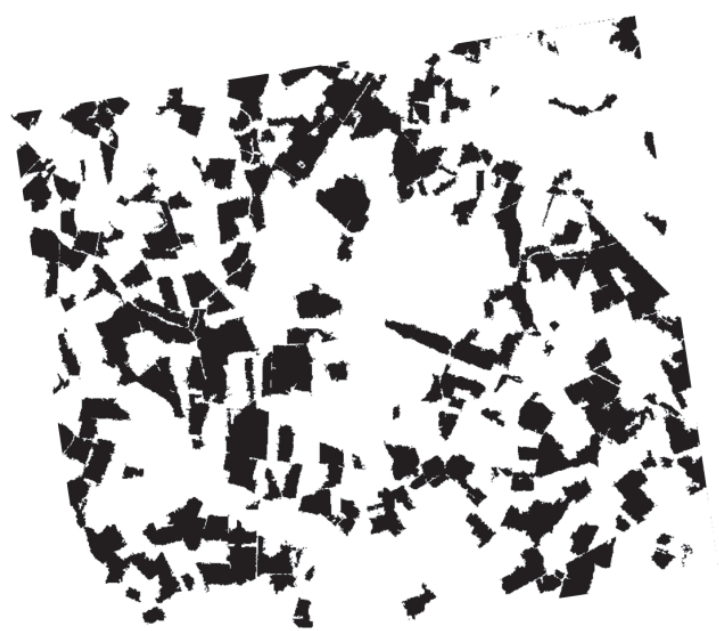

(a)

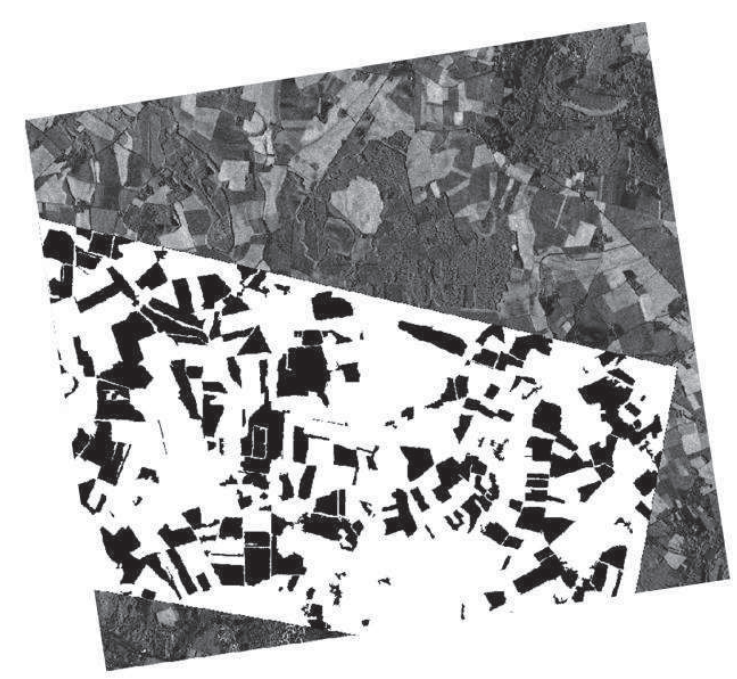

(b)

$\square$ Bare soils

Fig. 8. Bare soils map obtained from March 1, 2010 TerraSAR-X image (a) and the reference bare soils map (RapidEye) (b). Central coordinates: Lat. 4851 'N and Long. $3^{\circ} 07^{\prime}$ E (Orgeval). 


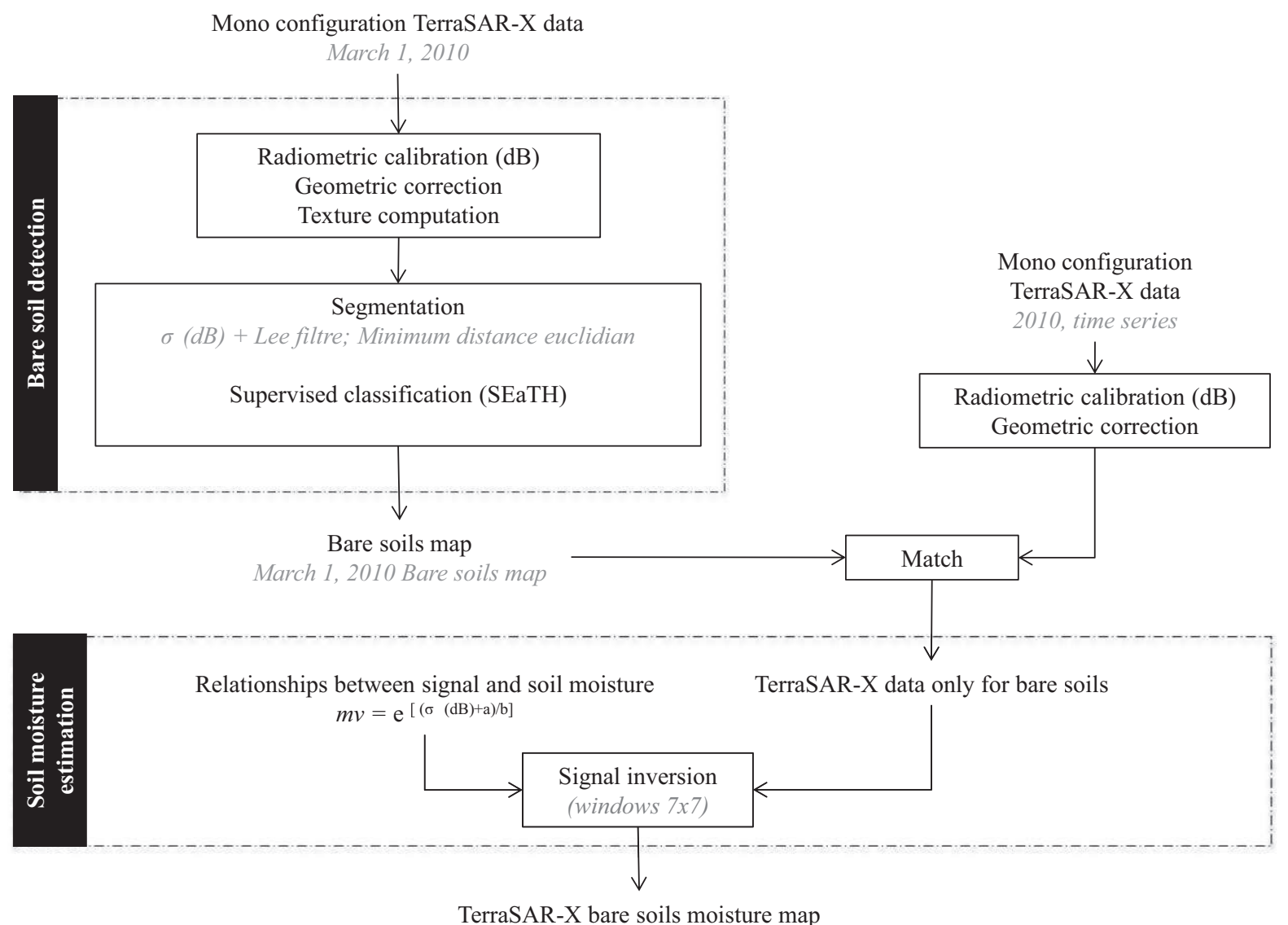

Fig. 9. Flowchart for the moisture mapping of bare soils. First phase: bare soil detection. Second phase: soil moisture estimation. 


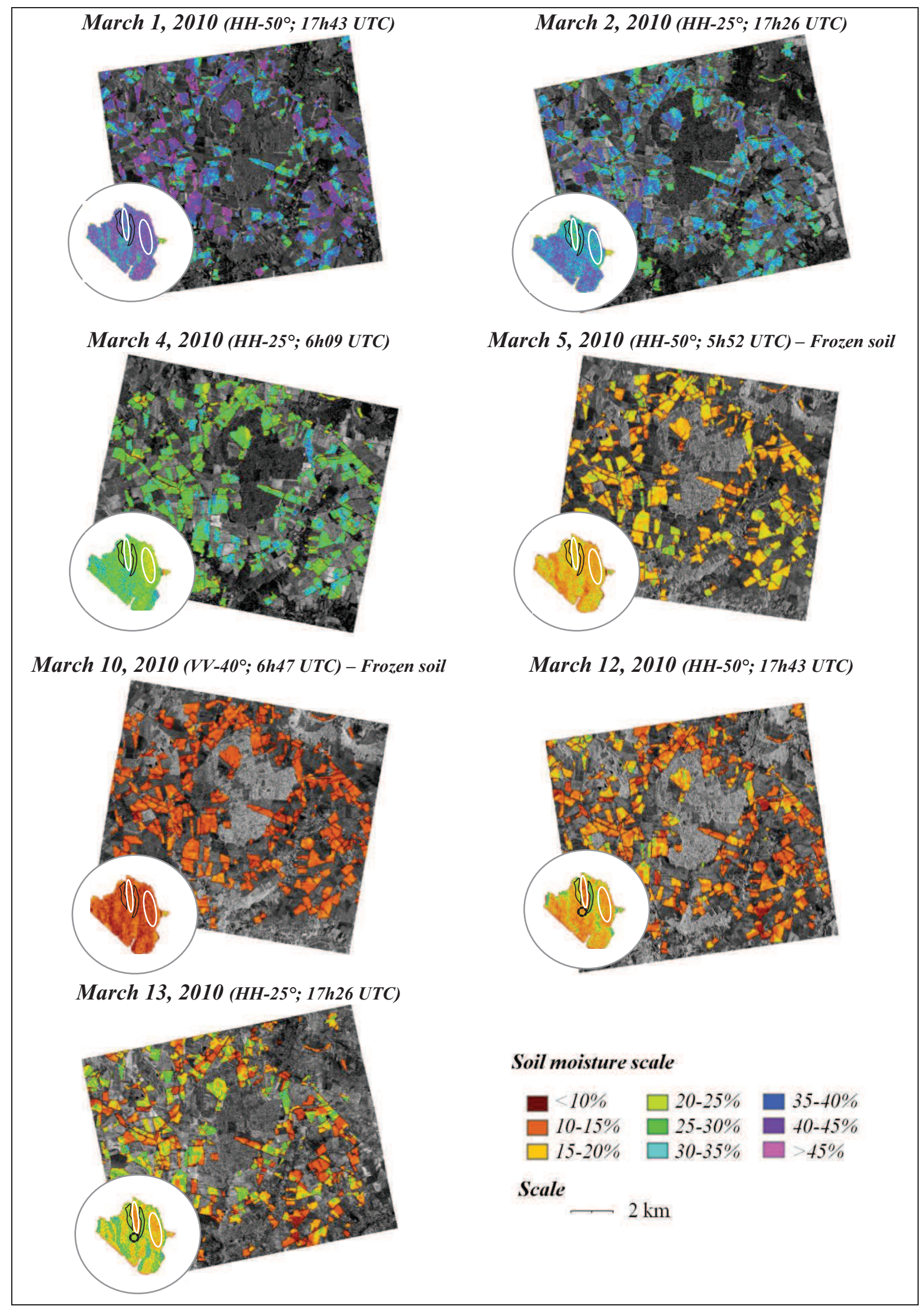

Fig. 10. Multitemporal evolution of bare soil moisture estimated from TerraSAR-X images acquired on the Orgeval watershed (BSMOM dataset). For each date, a zoomed representation of the variations in soil moisture within a training plot is presented. Soil I is outlined with a white line, and Soil II is outlined with a black line. The dotted black line shows soil II frozen on March 12 and thawed on March 13. 


\section{Tables}

Table 1. Characteristics of the TerraSAR-X images and in situ soil moisture measurements. SMAC: Soil Moisture Algorithm Calibration; BSD: Bare Soil Detection; SMAV: Soil Moisture Algorithm Validation; BSMOM: Bare Soil Moisture Operational Mapping. (* Frozen soil: data are only used in the soil moisture mapping of the BSMOM dataset.)

\begin{tabular}{|c|c|c|c|c|c|c|c|}
\hline Set & Site & $\begin{array}{c}\text { Acquisition } \\
\text { date } \\
\text { dd } / \mathbf{m m} / \mathbf{y y}\end{array}$ & $\begin{array}{l}\text { Incidence } \\
\text { angle }\end{array}$ & Polarization & $\begin{array}{l}\text { Number } \\
\text { of plots }\end{array}$ & $\begin{array}{l}\text { Roughness } \\
\text { (Hrms) } \\
\text { [Min; Max] }\end{array}$ & $\begin{array}{c}\text { In situ soil } \\
\text { moisture } \\
(\%) \\
{[\text { Min; Max] }}\end{array}$ \\
\hline \multirow{4}{*}{$\frac{u}{4}$} & \multirow{15}{*}{ Orgeval } & $12 / 02 / 08$ & $50^{\circ}$ & $\mathrm{HH}$ & 10 & {$[0.5 ; 3.3]$} & {$[31.4 ; 35.6]$} \\
\hline & & $13 / 02 / 08$ & $25^{\circ}$ & $\mathrm{HH}$ & 10 & {$[0.7 ; 3.3]$} & {$[31.0 ; 35.9]$} \\
\hline & & $15 / 02 / 08$ & $25^{\circ}$ & $\mathrm{HH}$ & 10 & {$[0.7 ; 3.3]$} & {$[30.6 ; 35.3]$} \\
\hline & & $30 / 04 / 08$ & $25^{\circ}$ & $\mathrm{HH}$ & 4 & - & {$[31.8 ; 32.9]$} \\
\hline \multirow{11}{*}{ 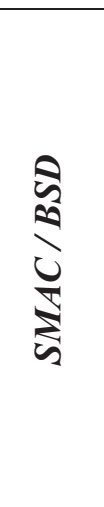 } & & $17 / 03 / 09$ & $25^{\circ}$ & $\mathrm{HH}$ & 9 & {$[1.8 ; 2.4]$} & {$[24.7 ; 32.3]$} \\
\hline & & $18 / 03 / 09$ & $50^{\circ}$ & $\mathrm{HH}$ & 10 & {$[1.8 ; 2.4]$} & {$[24.5 ; 29.8]$} \\
\hline & & $25 / 03 / 09$ & $50^{\circ}$ & $\mathrm{HH}$ & 3 & {$[2.3 ; 2.8]$} & {$[24.1 ; 31.0]$} \\
\hline & & $26 / 03 / 09$ & $25^{\circ}$ & $\mathrm{HH}$ & 10 & {$[1.8 ; 2.8]$} & {$[23.9 ; 32.7]$} \\
\hline & & 08/04/09 & $25^{\circ}$ & $\mathrm{HH}$ & 10 & {$[1.2 ; 2.5]$} & {$[16.8 ; 27.5]$} \\
\hline & & 09/04/09 & $50^{\circ}$ & $\mathrm{HH}$ & 10 & {$[1.3 ; 2.6]$} & {$[15.2 ; 26.3]$} \\
\hline & & $17 / 04 / 09$ & $25^{\circ}$ & $\mathrm{HH}$ & 8 & {$[1.0 ; 2.6]$} & {$[14.1 ; 16.4]$} \\
\hline & & 20/04/09 & $50^{\circ}$ & $\mathrm{HH}$ & 9 & {$[1.0 ; 2.6]$} & {$[18.3 ; 23.9]$} \\
\hline & & $27 / 04 / 09$ & $50^{\circ}$ & VV & 8 & {$[1.0 ; 4.6]$} & {$[10.4 ; 20.7]$} \\
\hline & & 28/04/09 & $25^{\circ}$ & VV & 8 & {$[1.0 ; 4.6]$} & {$[18.7 ; 26.9]$} \\
\hline & & $11 / 05 / 09$ & $25^{\circ}$ & $\mathrm{HH}$ & 5 & {$[1.0 ; 4.6]$} & {$[25.8 ; 31.3]$} \\
\hline \multirow{10}{*}{$\sum_{5}$} & & $15 / 03 / 10$ & $33^{\circ}$ & VV & 6 & {$[1.1 ; 2.6]$} & {$[9.7 ; 14.3]$} \\
\hline & & $17 / 03 / 10$ & $54^{\circ}$ & VV & 6 & {$[0.5 ; 1.6]$} & {$[8.4 ; 13.4]$} \\
\hline & Versailles & $18 / 03 / 10$ & $33^{\circ}$ & VV & 5 & {$[0.5: 1.4]$} & {$[8.5 ; 13.6]$} \\
\hline & & $26 / 03 / 10$ & $33^{\circ}$ & VV & 7 & {$[0.5 ; 2.4]$} & {$[17.2 ; 22.2]$} \\
\hline & & $27 / 03 / 10$ & $54^{\circ}$ & VV & 6 & {$[0.5 ; 2.4]$} & {$[18.1 ; 26.2]$} \\
\hline & & $29 / 03 / 10$ & $33^{\circ}$ & VV & 6 & {$[0.9 ; 2.4]$} & {$[13.3 ; 24.5]$} \\
\hline & & $15 / 01 / 08$ & $52^{\circ}$ & $\mathrm{HH}$ & 3 & {$[0.4 ; 2.9]$} & {$[27.8 ; 31.8]$} \\
\hline & & $16 / 01 / 08$ & $28^{\circ}$ & $\mathrm{HH}$ & 2 & {$[0.7 ; 3.0]$} & {$[27.8 ; 32.3]$} \\
\hline & Villamblain & $06 / 02 / 08$ & $52^{\circ}$ & $\mathrm{HH}$ & 8 & {$[0.6 ; 3.1]$} & {$[26.7 ; 34.0]$} \\
\hline & & $07 / 02 / 08$ & $28^{\circ}$ & $\mathrm{HH}$ & 9 & {$[0.7 ; 3.1]$} & {$[26.7 ; 34.0]$} \\
\hline \multirow{8}{*}{$\vec{z}$} & Yzeron & $12 / 03 / 09$ & $23^{\circ}$ & $\mathrm{HH}$ & 8 & - & {$[15.3 ; 24.3]$} \\
\hline & & $28 / 10 / 10$ & $52^{\circ}$ & VV & 13 & {$[0.8 ; 4.1]$} & {$[8.9 ; 14.7]$} \\
\hline & & $02 / 11 / 10$ & $41^{\circ}$ & VV & 11 & {$[0.8 ; 3.7]$} & {$[8.9 ; 18.7]$} \\
\hline & Thau & $04 / 11 / 10$ & $35^{\circ}$ & VV & 10 & {$[0.8 ; 3.7]$} & {$[5.7 ; 11.4]$} \\
\hline & & $15 / 11 / 10$ & $35^{\circ}$ & VV & 10 & {$[1.3 ; 3.7]$} & {$[8.3 ; 19.8]$} \\
\hline & & $18 / 11 / 10$ & $26^{\circ}$ & VV & 9 & {$[0.8 ; 3.7]$} & {$[6.8 ; 14.5]$} \\
\hline & Garon & $09 / 06 / 09$ & $49^{\circ}$ & $\mathrm{HH}$ & 6 & {$[0.9 ; 2.9]$} & {$[24.9 ; 40.6]$} \\
\hline & Garon & $11 / 06 / 09$ & $25^{\circ}$ & $\mathrm{HH}$ & 6 & {$[0.9 ; 2.9]$} & {$[10.3 ; 26.4]$} \\
\hline \multirow{7}{*}{ 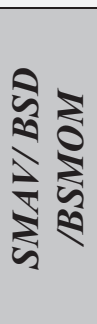 } & & $01 / 03 / 10$ & $50^{\circ}$ & $\mathrm{HH}$ & 6 & {$[1.8 ; 2.8]$} & {$[33.4 ; 39.8]$} \\
\hline & & $02 / 03 / 10$ & $25^{\circ}$ & $\mathrm{HH}$ & 6 & {$[1.9 ; 2.8]$} & {$[32.7 ; 39.0]$} \\
\hline & & $04 / 03 / 10$ & $25^{\circ}$ & $\mathrm{HH}$ & 8 & {$[1.9 ; 2.8]$} & {$[27.3 ; 34.3]$} \\
\hline & Orgeval & $05 / 03 / 10^{*}$ & $50^{\circ}$ & $\mathrm{HH}$ & 8 & {$[1.8 ; 2.8]$} & {$[27.6 ; 33.5]$} \\
\hline & & $10 / 03 / 10^{*}$ & $40^{\circ}$ & VV & 9 & {$[1.1 ; 2.8]$} & {$[13.4 ; 22.5]$} \\
\hline & & $12 / 03 / 10$ & $50^{\circ}$ & $\mathrm{HH}$ & 10 & {$[1.1 ; 2.8]$} & {$[12.6 ; 29.0]$} \\
\hline & & $13 / 03 / 10$ & $25^{\circ}$ & $\mathrm{HH}$ & 9 & {$[1.9 ; 2.6]$} & {$[14.9 ; 26.3]$} \\
\hline
\end{tabular}


Table 2. Main characteristics of optical data acquired over the Orgeval. NIR=Near Infrared; MIR= Mid-Infrared

\begin{tabular}{c|c|c|c|c}
\hline Study site & $\begin{array}{c}\text { Acquisition date } \\
\mathbf{d d} / \mathbf{m m} / \mathbf{y y}\end{array}$ & Sensor & Resolution $\mathbf{( m )}$ & Bands \\
\hline \multirow{3}{*}{ Orgeval } & $14 / 03 / 09$ & IKONOS-2 & 4 & Blue, Green, Red, NIR \\
& $23 / 04 / 09$ & SPOT-5 & 10 & Green, Red, PIR, MIR \\
& $26 / 05 / 10$ & RapidEye & 5 & Blue, Green, Red, Red Edge, NIR \\
\hline
\end{tabular}

Table 3. Multiresolution segmentation parameters used for optical data.

\begin{tabular}{c|c|ccc}
\hline \multirow{2}{*}{$\begin{array}{c}\text { Acquisition } \\
\text { date }\end{array}$} & Input & \multicolumn{3}{|c}{ Segmentation parameters } \\
dd/mm/yy & & Scale & Shape & Compactness \\
\hline $14 / 03 / 09$ & NDVI IKONOS-2 & 90 & 0.1 & 0.7 \\
$23 / 04 / 09$ & NDVI SPOT-5 & 30 & 0.1 & 0.5 \\
$26 / 05 / 10$ & NDVI RapidEye & 80 & 0.1 & 0.7 \\
\hline
\end{tabular}

Table 4: Comparison of the soil moistures estimated from TerraSAR-X data and those measured in situ (SMAV dataset). Bias corresponds to the difference between the in situ measurements and the estimated data.

\begin{tabular}{c|cc|c|cc|cccc}
\hline Study site & \multicolumn{2}{|c|}{ Orgeval } & Yzeron & \multicolumn{2}{|c|}{ Garon } & \multicolumn{3}{|c}{ Thau } \\
& 2010 & & \multicolumn{2}{|c|}{} & & & \\
\hline Polarization & \multicolumn{2}{|c|}{$\mathrm{HH}$} & $\mathrm{HH}$ & \multicolumn{2}{|c|}{$\mathrm{HH}$} & $\mathrm{VV}$ & $\mathrm{VV}$ \\
Incidence angle $\left(^{\circ}\right.$ ) & 25 & 50 & 23 & 25 & 49 & $26-35$ & 41 & 52 \\
\hline Number of training plots & 22 & 15 & 8 & 6 & 6 & 29 & 11 & 13 \\
\hline Bias (vol. \%) & -1.0 & 1.2 & -1.6 & 0.8 & -1.0 & 2.5 & 1.2 & 1.4 \\
RMSE (vol. \%) & 3.5 & 5.0 & 2.9 & 3.4 & 4.3 & 4.1 & 2.5 & 4.0 \\
\hline
\end{tabular}

Table 5. Signal and texture features computed from each training plot and from each TerraSAR-X image of the BSD dataset.

\begin{tabular}{|c|c|c|c|}
\hline \multirow[b]{3}{*}{ Signal } & \multicolumn{3}{|c|}{ Texture feature } \\
\hline & \multirow[b]{2}{*}{$\begin{array}{c}\text { Irons \& } \\
\text { Petersen } \\
(1981)\end{array}$} & \multicolumn{2}{|c|}{ Haralick et al. (1973) } \\
\hline & & $\begin{array}{c}\text { GLCM } \\
\text { Gray Level Co-occurrence } \\
\text { Matrices }\end{array}$ & $\begin{array}{c}\text { GLDV } \\
\text { Gray Level Difference } \\
\text { Vector }\end{array}$ \\
\hline $\begin{array}{l}\text { Mean } \\
\text { Standard } \\
\text { Deviation }\end{array}$ & $\begin{array}{l}\text { Mean } \\
\text { Euclidian } \\
\text { Distance } \\
\text { Variance } \\
\text { Kurtosis } \\
\text { Skewness }\end{array}$ & $\begin{array}{l}\text { GLCM mean } \\
\text { GLCM standard deviation } \\
\text { GLCM homogeneity } \\
\text { GLCM correlation } \\
\text { GLCM contrast } \\
\text { GLCM dissimilarity } \\
\text { GLCM entropy } \\
\text { GLCM angular } 2^{\text {nd }} \text { moment }\end{array}$ & $\begin{array}{l}\text { GLDV mean } \\
\text { GLDV angular } 2^{\text {nd }} \\
\text { moment } \\
\text { GLDV entropy } \\
\text { GLDV contrast }\end{array}$ \\
\hline 2 & 4 & 8 features $x 5$ directions $=40$ & $\begin{array}{c}4 \text { features } x 5 \\
\text { directions }=20\end{array}$ \\
\hline
\end{tabular}


Table 6. Confusion matrix and kappa statistics for the March 1, 2010 TerraSAR-X bare soil map.

\begin{tabular}{|c|c|c|c|c|c|c|c|c|c|}
\hline & \multicolumn{4}{|c|}{ TerraSAR-X pixel-based accuracy } & \multicolumn{4}{|c|}{ TerraSAR-X object-based accuracy } \\
\hline & & Bare soils & Other & Sum & $\begin{array}{c}\text { Omission } \\
\text { error }\end{array}$ & Bare soils & Other & Sum & $\begin{array}{c}\text { Omission } \\
\text { error }\end{array}$ \\
\hline \multirow{4}{*}{ 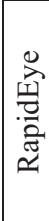 } & Bare soil & 21750510 & 5669951 & 27420461 & $20.7 \%$ & 96 & 17 & 113 & \multirow{4}{*}{$\begin{array}{l}9.5 \% \\
6.7 \%\end{array}$} \\
\hline & Other & 8031576 & 53711156 & 61742732 & \multirow[t]{3}{*}{$13.0 \%$} & 6 & 182 & 188 & \\
\hline & Sum & 29782086 & 59381107 & 89163193 & & 102 & 199 & 301 & \\
\hline & $\begin{array}{c}\text { Commission } \\
\text { error }\end{array}$ & $27.0 \%$ & $9.5 \%$ & & & $11.2 \%$ & $5.7 \%$ & & \\
\hline \multicolumn{2}{|c|}{ Overall accuracy } & \multicolumn{4}{|c|}{$84.6 \%$} & \multicolumn{4}{|c|}{$92.2 \%$} \\
\hline & Kappa & \multicolumn{4}{|c|}{0.65} & \multicolumn{4}{|c|}{0.83} \\
\hline
\end{tabular}

Table 7. Comparison of three classification methods used to create bare soils maps from the TerraSAR-X images.

\begin{tabular}{c|c|c|c}
\hline Process & \multicolumn{2}{|c|}{ Supervised } & Unsupervised \\
\hline Segmentation & \multicolumn{2}{|c|}{ Digitalization } & TerraSAR-X multi-résolution segmentation \\
\hline Classification & \multicolumn{2}{|c|}{$\begin{array}{c}\text { Supervised object: } \\
\text { SEaTH on training areas }\end{array}$} & $\begin{array}{c}\text { Unsupervised object: } \\
\text { Isodata }\end{array}$ \\
\hline $\begin{array}{c}\text { Overall accuracy } \\
\text { (pixel /object) }\end{array}$ & $94.4 / 94.3 \%$ & $84.6 / 92.2 \%$ & $84.2 / 93.6 \%$ \\
\hline $\begin{array}{c}\text { Kappa value } \\
\text { (pixel/object) }\end{array}$ & $0.86 / 0.88$ & $0.65 / 0.83$ & $0.64 / 0.86$ \\
\hline
\end{tabular}

Table 8. Comparison of the estimated and measured mean soil moistures over the Orgeval watershed. Mean values and standard deviations are shown.

\begin{tabular}{c|ccccccc}
\hline Date (dd/mm/yy) & $01 / 03 / 10$ & $02 / 03 / 10$ & $04 / 03 / 10$ & $05 / 03 / 10$ & $10 / 03 / 10$ & $12 / 03 / 10$ & $13 / 03 / 10$ \\
\hline $\begin{array}{c}\text { Average estimate of soil } \\
\text { moisture on the watershed } \\
(\%)\end{array}$ & $\begin{array}{c}36.3 \\
\pm 11.1\end{array}$ & $\begin{array}{c}33.7 \\
\pm 9.1\end{array}$ & $\begin{array}{c}27.8 \\
\pm 7.8\end{array}$ & $\begin{array}{c}17.7 \\
\pm 5.7\end{array}$ & $\begin{array}{c}12.2 \\
\pm 3.6\end{array}$ & $\begin{array}{c}14.7 \\
\pm 5.4\end{array}$ & $\begin{array}{c}17.5 \\
\pm 7.0\end{array}$ \\
\hline $\begin{array}{c}\text { Average of soil moisture } \\
\text { measurements over 6 training } \\
\text { plots }\end{array}$ & 37.2 & 35.6 & 31.6 & 30.4 & 20.0 & 18.0 & 19.1 \\
\pm 2.9 & \pm 2.3 & \pm 3.5 & \pm 2.6 & \pm 3.0 & \pm 2.8 & \pm 2.7 \\
\hline
\end{tabular}

